\title{
pH-Triggered Release Performance of Microcapsule-Based Inhibitor and Its Inhibition Effect on the Reinforcement Embedded in Mortar
}

\author{
Jinzhen Huang ${ }^{1,2,+}$, Yangyang Zhu ${ }^{1,3, \dagger}$, Yuwei Ma ${ }^{4}$, Jie Hu ${ }^{1, *}$, Haoliang Huang ${ }^{1, *}$, Jiangxiong Wei ${ }^{1, *}$ \\ and Qijun Yu ${ }^{1}$
}

1 School of Materials Science and Engineering, South China University of Technology, Guangzhou 510640, China; msjinzhenh@mail.scut.edu.cn (J.H.); zhuyy10@vanke.com (Y.Z.); concyuq@scut.edu.cn (Q.Y.)

2 Southern Marine Science and Engineering Guangdong Laboratory (Zhanjiang), Zhanjiang 524006, China

3 China Vanke Co., Ltd., Shenzhen 518020, China

4 Research Center for Wind Engineering and Engineering Vibration, Guangzhou University, Guangzhou 510006, China; yuwei_ma@gzhu.edu.cn

* Correspondence: msjiehu@scut.edu.cn (J.H.); huanghaoliang@scut.edu.cn (H.H.); jxwei@scut.edu.cn (J.W.); Tel.: +86-2087114137 (J.H. \& H.H. \& J.W.); Fax: +86-2087114137 (J.H. \& H.H.); +86-2087114133 (J.W.)

+ Equal contribution to this work.

Citation: Huang, J.; Zhu, Y.; Ma, Y.; Hu, J.; Huang, H.; Wei, J.; Yu, Q. $\mathrm{pH}$-Triggered Release Performance of Microcapsule-Based Inhibitor and Its Inhibition Effect on the

Reinforcement Embedded in Mortar. Materials 2021, 14, 5517. https:// doi.org/10.3390/ma14195517

Academic Editor: Frédéric Skoczylas

Received: 29 August 2021

Accepted: 20 September 2021

Published: 23 September 2021

Publisher's Note: MDPI stays neutral with regard to jurisdictional claims in published maps and institutional affiliations.

Copyright: (c) 2021 by the authors. Licensee MDPI, Basel, Switzerland. This article is an open access article distributed under the terms and conditions of the Creative Commons Attribution (CC BY) license (https:/ / creativecommons.org/licenses/by/ $4.0 /)$.

\begin{abstract}
The smart release of healing agents is a key factor determining the inhibition efficiency of microcapsules-based corrosion inhibitors for reinforced concrete. In this study, the release behavior of benzotriazole (BTA) in microcapsule-based inhibitors was investigated in mortar sample to clarify the influence of different hydration products on the release process. The results indicated that under high $\mathrm{pH}$ environment $(\mathrm{pH}>12.4)$, only about $5 \%$ reserved BTA was released from the mortar sample. $\mathrm{pH}$ drop resulted in the increased release of BTA from mortar sample. Most BTA in the microcapsule-based inhibitors was released from mortar sample in low $\mathrm{pH}$ environment, which was closely related to morphology/composition alterations of hydration products caused by $\mathrm{pH}$ drop of the environment. The smart release of BTA dramatically delayed corrosion initiation of reinforced mortar and halted corrosion product accumulation on the steel surface. Therefore, the corrosion resistance of the reinforced mortar was improved after corrosion initiation.
\end{abstract}

Keywords: microcapsule-based inhibitors; composition alterations; release behavior; mortar; $\mathrm{pH}$ sensitive; corrosion resistance

\section{Introduction}

Corrosion of the steel bar is widely accepted as the important factor causing the damage of reinforced concrete. Chlorides and carbonation are two main reasons initiating corrosion of the steel bar. Carbonation causes the neutralization of cement-based materials and subsequently $\mathrm{pH}$ drop from 13 to about 8-9 [1]; pit corrosion can be initiated when sufficient chlorides penetrate at the reinforcing steel/concrete interface, and $\mathrm{pH}$ at corrosion sites is lower than $5[1,2]$, leading to more serious corrosion damage and reduced service life of reinforcement concrete $[3,4]$.

The addition of organic corrosion inhibitors is an efficient way to protect reinforced concrete from corrosion damage [5-7]. Normally, organic corrosion inhibitors form an adsorption film on the reinforcing steel surface, reducing anode or cathode reaction rate during corrosion process and subsequently improving the corrosion resistance of the reinforcing steel [8]. However, some adverse impacts of organic corrosion inhibitors were reported when used in concrete. For example, corrosion inhibitors based on amine and ester increased the pore size and subsequently water permeability of concrete [9], which would reduce the durability of reinforced concrete. Further, because the traditional organic 
corrosion inhibitors are not sensitive to environment alterations (i.e., $\mathrm{pH}$ reduction or $\mathrm{Cl}^{-}$ content increase) at the local corrosion sites, the corrosion damage of the reinforcement is not able to be targeted repaired immediately after corrosion initiation.

In recent years, microcapsules carrying with self-healing agents were proposed for achieving smart corrosion protection of reinforced concrete [10-14]. For example, microcapsules with calcium hydroxide core and ethocel shell maintained high $\mathrm{OH}^{-}$concentration in cement pore solution due to the accelerated release (about 10\% higher) of the encapsulated $\mathrm{Ca}(\mathrm{OH})_{2}$ when $\mathrm{pH}$ decreased, thus halting corrosion of the immersed reinforcing steel $[11,14]$. It was also reported that the released amount of sodium nitrite or sodium monofluorophosphate from microcapsules with ethocel or polystyrene resin shell was increased by $10 \%$ in low $\mathrm{pH}$ simulated cement pore solution (SPS) [10,15]. Liu et al. [16] prepared $\mathrm{CaCO}_{3}$ microparticles loaded with sodium lignosulfonate (SLS). The results indicated that the loaded SLS was released under different $\mathrm{pH}$ conditions of the aqueous media; however, SLS release amount in acidic testing solution $(\mathrm{pH}=4)$ was about $50-80 \%$ higher than in alkaline testing solution $(\mathrm{pH}=10)$. Ress et al. [17] synthesized microcapsules with $\mathrm{NaNO}_{2}$ core and colophony shell for corrosion protection of reinforced concrete to avoid the leaching of $\mathrm{NaNO}_{2}$ from concrete admixture. Pronounced $\mathrm{pH}$ sensitivity was observed for the prepared microcapsules: the released amount of $\mathrm{NaNO}_{2}$ was doubled in alkaline simulated concrete pore solution, compared to neutral Di water. Even though the above microcapsules avoid the leaching of $\mathrm{NaNO}_{2}$, its application for smart corrosion control of reinforced concrete should be further clarified, because the corrosion damage of the reinforcement is accompanied by $\mathrm{pH}$ drop from 13 to about 8-9. Furthermore, chloride-triggered microcapsules with $\mathrm{Ca}(\mathrm{OH})_{2}$ core and cross-linked poly-ionic liquids shell were also reported [18]. The presence of chloride in the testing solution resulted in a large amount of nanometer-sized holes on the shell, accelerating the release of $\mathrm{Ca}(\mathrm{OH})_{2}$. It can be found that the above proposed microcapsules exhibit $\mathrm{pH}$ sensitivity, thus are good candidates as the self-healing materials for reinforced concrete. However, $\mathrm{pH}$ sensitivity of the microcapsules can still be potentially increased.

In our previous studies $[19,20]$, tailored microcapsule-based corrosion inhibitors (MCI) with no significantly harmful impact on cement-based materials was successfully prepared. Very high $\mathrm{pH}$ sensitivity was relevant for the prepared MCI: on one hand, the prepared MCI presented a high stability in SPS with $\mathrm{pH}$ of 13; on the other hand, 5 times higher amount of the released benzotriazole (BTA) was observed in SPS with pH lower than 11. Cement-based materials are much more complicated than SPS, and different hydration products will also significantly affect the release behavior of healing agents encapsulated in MCI. Therefore, it is of great importance to verify its $\mathrm{pH}$ sensitivity in cement-based materials before the above microcapsule-based corrosion inhibitors are used for smart corrosion control of reinforced concrete. To this end, the release performance of healing agents encapsulated in MCI was extensively characterized in mortar, and the relationship between the release behavior and composition/microstructure alterations of hydration products was clarified in this present study. Further, the corrosion inhibition effect of MCI on the reinforcement embedded in mortar was also evaluated.

\section{Materials and Methods}

\subsection{Materials}

Amphiphilic polyethylene oxide $\left(\mathrm{PEO}_{113}\right)$-b-polystyrene $\left(\mathrm{PS}_{1171}\right)$ copolymer was used to prepare microcapsule-based corrosion inhibitor (MCI) by dialysis in this study; the details related to the preparation procedure, copolymers and MCI can be found in $[19,20]$. The concentration of benzotriazole (BTA) encapsulated in $\mathrm{MCI}$ was $2.10 \mathrm{mg} / \mathrm{mg}$ and the concentration of MCI solution was $0.5 \mathrm{~g} / \mathrm{L}$ the average diameter of MCI was about $250 \mathrm{~nm}[19,20]$.

Simulated cement pore solution (SPS) in this study contained $0.06 \mathrm{~mol} / 1$ sodium hydroxide and saturated calcium hydroxide (with $\mathrm{pH}$ of 12.7) [7]. In order to clarify the influence of $\mathrm{pH}$ on the release amount of BTA reserved in MCI, $\mathrm{pH}$ of SPS was changed to $12.4,11.5,9$ and 7 , respectively. 
Both mortar sample and reinforced mortar samples with dimensions of $40 \mathrm{~mm} \times 40 \mathrm{~mm}$ $\times 160 \mathrm{~mm}$ were cast by using PII 42.5 ordinary Portland cement with the chemical and mineral compositions as shown in Tables 1 and 2, respectively. $\mathrm{D}_{50}$ (maximum particle size when accumulative volume of cement reached $50 \mathrm{vol} . \%$ ) of the used cement was $24 \mu \mathrm{m}$ in this study (as shown in Figure 1). For reinforced mortar, the used reinforcement was HPB235 construction reinforcement (the chemical compositions are presented in Table 3); the diameter and working area of the used reinforcement was $8 \mathrm{~mm}$ and $35.2 \mathrm{~cm}^{2}$, respectively. The water to cement $(w / c)$ ratio and cement to sand $(c / s)$ ratio for (reinforced) mortar were 0.5 and 1:3. For mortar samples, the mixing water was $\mathrm{MCI}$ solution. For reinforced mortar samples, the mixing water was deionized water for the reference MCI-free sample and MCI solution for the MCI-containing sample. As a result, $\mathrm{MCI}$ concentration in (reinforced) mortar was $0.025 \mathrm{wt}$. \% (per dry cement weight); correspondingly, BTA concentration in (reinforced) mortar was $0.0525 \mathrm{wt}$. \% (per dry cement weight). The curing condition for (reinforced) mortar sample was $20{ }^{\circ} \mathrm{C}$ and $95 \% \mathrm{RH}$. At 28 days, mortar samples were crushed into small pieces and then ground into fine powders. $1.0 \mathrm{~g}$ mortar powders were immersed in $20 \mathrm{~mL}$ SPS with difference $\mathrm{pH}$ values for $3 \mathrm{~d}$; centrifugation was then conducted with the relevant SPS for $10 \mathrm{~min}$ at $4800 \mathrm{rpm}$. The collected solution by filtering with $0.45 \mu \mathrm{m}$ filter film was used to characterize the released BTA amount in SPS. Further, the mortar powders collected after centrifugation were used to investigate the alterations on morphology and compositions of hydration products in mortar samples. Before the above tests, the collected mortar powders were immersed in ethanol for $48 \mathrm{~h}$ to stop hydration. In our previous study [19], after PEO-b-PS copolymers were synthesized, the products were purified by precipitating in methanol for three times before the preparation of MCI. As a result, it was believed that PEO-b-PS copolymers and MCI should be very stable in ethanol and the immersion in ethanol should not exhibit obvious effect on MCI in this present study. After immersion, the mortar powders were separated from ethanol by filtration with $0.45 \mu \mathrm{m}$ filter film and dried at $40{ }^{\circ} \mathrm{C}$ in vacuum drying chamber until constant weight. After curing for 28 days, reinforced mortar samples were half soaked in $3.5 \mathrm{wt}$. \% NaCl solution for further investigations.

Table 1. Chemical composition of PII 42.5 Portland cement (wt. \%).

\begin{tabular}{cccccccccc}
\hline $\mathrm{SiO}_{2}$ & $\mathrm{Al}_{2} \mathrm{O}_{3}$ & $\mathrm{Fe}_{2} \mathrm{O}_{3}$ & $\mathrm{CaO}$ & $\mathbf{M g O}$ & $\mathrm{K}_{2} \mathrm{O}$ & $\mathrm{Na}_{2} \mathrm{O}$ & $\mathrm{SO}_{3}$ & Others & LOI \\
\hline 21.60 & 4.35 & 2.95 & 63.81 & 1.76 & 0.51 & 0.16 & 2.06 & 1.61 & 1.19 \\
\hline${ }^{*}$ LOI, loss on ignition. & & & & & & &
\end{tabular}

Table 2. Mineral composition of P.II 42.5 Portland cement (wt. \%).

\begin{tabular}{cccccc}
\hline $\mathrm{C}_{3} \mathbf{S}^{*}$ & $\mathrm{C}_{2} \mathbf{S}^{*}$ & $\mathrm{C}_{3} \mathbf{A}{ }^{*}$ & $\mathbf{C}_{4} \mathbf{A F}{ }^{*}$ & $\mathrm{CaSO}_{4} \cdot 2 \mathbf{H}_{2} \mathbf{O}$ & $\mathrm{CaCO}_{3}$ \\
\hline 56.20 & 19.61 & 6.54 & 8.97 & 4.33 & 4.35 \\
\hline${ }^{*}$ Calculated by Bogue method [21]. & & &
\end{tabular}

Table 3. Chemical composition of HPB235 construction steel used in this study.

\begin{tabular}{cccccc}
\hline \multicolumn{5}{c}{ Elements Composition (wt. \%) } \\
\hline $\mathrm{C}$ & $\mathrm{Si}$ & $\mathrm{Mn}$ & $\mathrm{S}$ & $\mathrm{P}$ & $\mathrm{Fe}$ \\
0.18 & 0.28 & 0.55 & 0.04 & 0.04 & 98.91 \\
\hline
\end{tabular}

\subsection{Methods}

\subsubsection{Compressive Strength and Flexural Strength}

The dimensions of mortar samples for compressive strength and flexural strength tests were $40 \times 40 \times 40 \mathrm{~mm}^{3}$ and $40 \times 40 \times 160 \mathrm{~mm}^{3}$, respectively. The measurements of mechanical properties were conducted at the hydration age of $1 \mathrm{~d}, 3 \mathrm{~d}, 7 \mathrm{~d}$ and $28 \mathrm{~d}$, respectively. There were 3 replicates for each specimen. 


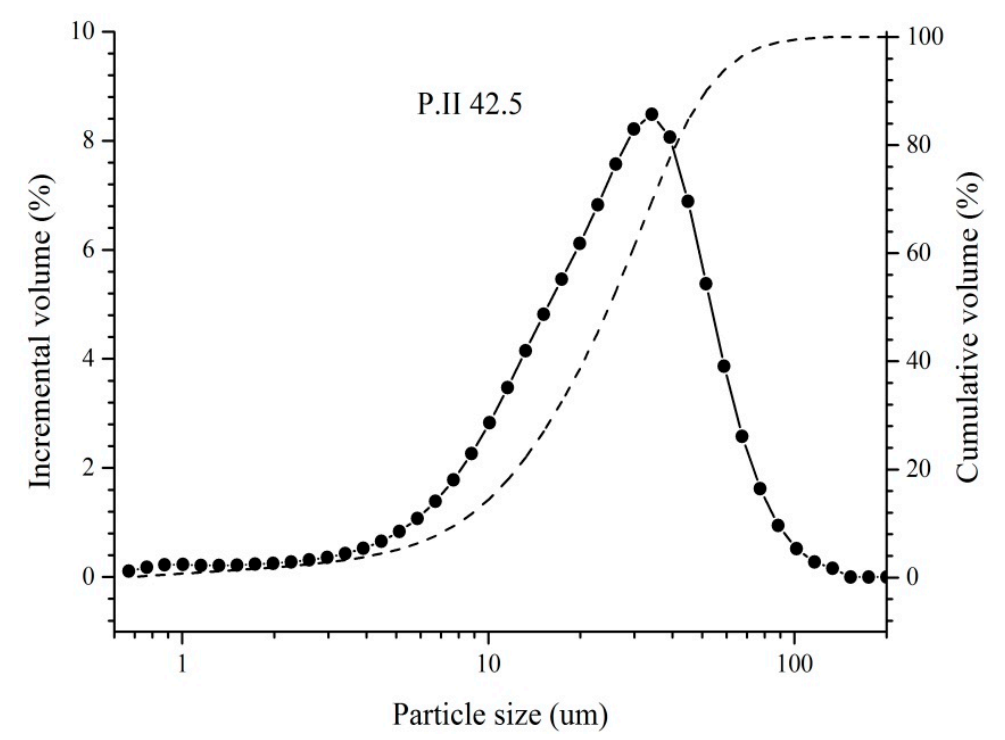

Figure 1. Particle size distribution of P.II 42.5 Portland cement used in this study.

\subsubsection{Release Amount of BTA Encapsulated in MCI}

In this study, UV-vis spectrophotometry (HEXIOS Gamma and Delta, Thermo Scientific, Waltham, MA, USA) was used to evaluate the released amount of BTA in SPS with a wavelength of $265 \mathrm{~nm}$. The background value for UV-vis spectrophotometry tests was determined by measuring the absorbance of SPS without MCI. The released percentage of BTA was expressed in Equation (1):

$$
M_{r}=C_{0} V_{s} / M_{m}
$$

where $M_{r}$ is the released percentage of BTA; $C_{0}$ is the measured BTA concentration in SPS; vs. is SPS volume used for the immersion of mortar sample; $M_{m}$ is BTA content in $1.0 \mathrm{~g}$ mortar sample.

\subsubsection{Morphology and Composition of the Mortar Samples}

In this study, scanning electronic microscope (SEM, EVO18, Zeiss, Oberkochen, Germany) was used for morphology observations of mortar sample after 3 days immersion with the magnifications of $100 \times$ and $5000 \times(10 \mathrm{kV}$ in second electronic (SE) mode). Both EDS (Merlin Compact VP, Oxford, Abingdon, England) and XRF (Axios Pw 4400, PANalytical B.V., Almelo, Netherland) were applied to evaluate the chemical compositions of mortar sample. The capacity of X-ray tube at Rhodium (Rh) target window was $4 \mathrm{~kW}$ and the accuracy was $0.05 \%$ for XRF analysis.

The mineral composition of mortar sample after immersed in SPS for 3 days was determined by XRD analysis (X'pert PRO, PANalytical B.V., Almelo, The Netherland). XRD analysis with energy source of $\mathrm{Cu} \mathrm{K} \mathrm{K}_{\mathrm{a}}(40 \mathrm{kV}$ and $40 \mathrm{~mA})$ was conducted between $5-90^{\circ}$ with scan rate of $10^{\circ} / \mathrm{min}$ and wavelength of $0.15 \mathrm{~nm}$. The main function groups (i.e., Al-O and $\mathrm{Si}-\mathrm{O}$ ) of hydration products in mortar samples were examined by FTIR (Nicolet Nexus for Euro, Thermo Scientific, Waltham, MA, USA) in this study. The scan number was 32 with the collected wavenumber between $400 \mathrm{~cm}^{-1}$ and $4000 \mathrm{~cm}^{-1}$. The resolution of FTIR tests was $0.4 \mathrm{~cm}^{-1}$. The polymerization degree of ${ }^{29} \mathrm{Si}$ and ${ }^{27} \mathrm{Al}$ for hydration products in mortar samples was investigated by NMR (AVANCE III HD 600, Bruker, Karlsruhe, Germany). The detector used for NMR tests was CP/MAS solid detector (Bruker, Karlsruhe, Germany). The used magnetic intensity was $400 \mathrm{~T}$ and the magic angle rotation rate was $15 \mathrm{kHz}$. The scanning number for NMR tests was 128 . 


\subsubsection{Electrochemical Behavior of Reinforced Mortar}

The electrochemical behavior of reinforced mortar was characterized by open circuit potentials $(\mathrm{OCP})$ and potentio-dynamic polarization (PD) at different immersion time intervals $(21 \mathrm{~d}, 72 \mathrm{~d}, 85 \mathrm{~d}, 92 \mathrm{~d}, 115 \mathrm{~d}$ and $135 \mathrm{~d})$. As three-electrode set-up, the reference electrode, working electrode and counter electrode was saturated calomel electrode (SCE), reinforcement electrode and Ti mesh, respectively. At $25 \pm 1{ }^{\circ} \mathrm{C}$, PD (Metrohm AutolabPotentiostat PGSTAT $302 \mathrm{~N}$ ) was tested from $-200 \mathrm{mV}$ to $+1000 \mathrm{mV}$ vs. OCP of the reinforcing steel with the scan rate of $0.5 \mathrm{mV} / \mathrm{s}$.

\subsubsection{Surface Analysis of the Reinforcement Embedded in Mortar}

After $135 \mathrm{~d}$, reinforced mortar samples were vacuum dried at $60^{\circ} \mathrm{C}$ for 1 day. The reinforced mortar was then broken and the morphology of the reinforcement surface was examined by SEM observations. $20 \mathrm{kV}$ was used as the accelerating voltage for SEM observations and images (in SE mode, with a magnification of $500 \times$ ) of the reinforcement surface were derived. Further, backscattered electronic (BSE) images (magnification of 200×) at the reinforcement/mortar interface were also obtained to characterize the accumulation of corrosion products after the treatment.

The chemical composition of the corrosion products was characterized by Raman analysis (LabRAM Aramis, HORIBA JobinYvon S.A.S, Kyoto, Japan) with magnification of $50 \times$ and power of $0.5 \mathrm{~mW}$. The wavelength of the used laser and cumulative scanning number for Raman analysis was $514.5 \mathrm{~nm}$ and 200, respectively. The exposure time for Raman analysis was $1 \mathrm{~s}$.

\section{Results}

\subsection{Mechanical Properties of Mortar Sample in the Presence of MCI}

Figure 2 shows the compressive strength and flexural strength of mortar samples at different hydration ages. It was observed that MCI-containing mortar sample exhibited similar compressive strength at early hydration ages $(1 \mathrm{~d}, 3 \mathrm{~d}$ and $7 \mathrm{~d})$. At 28 days, the compressive strength of the mortar sample was slightly increased in the presence of MCI: the compressive strength of MCI-free and MCI-containing mortar sample was about $60 \mathrm{MPa}$ and $70 \mathrm{MPa}$, respectively. MCI exhibited no obvious influence on the flexural strength of mortar sample in this present study. It indicated that the addition of MCI presented no negative effect on the mechanical properties of mortar samples.

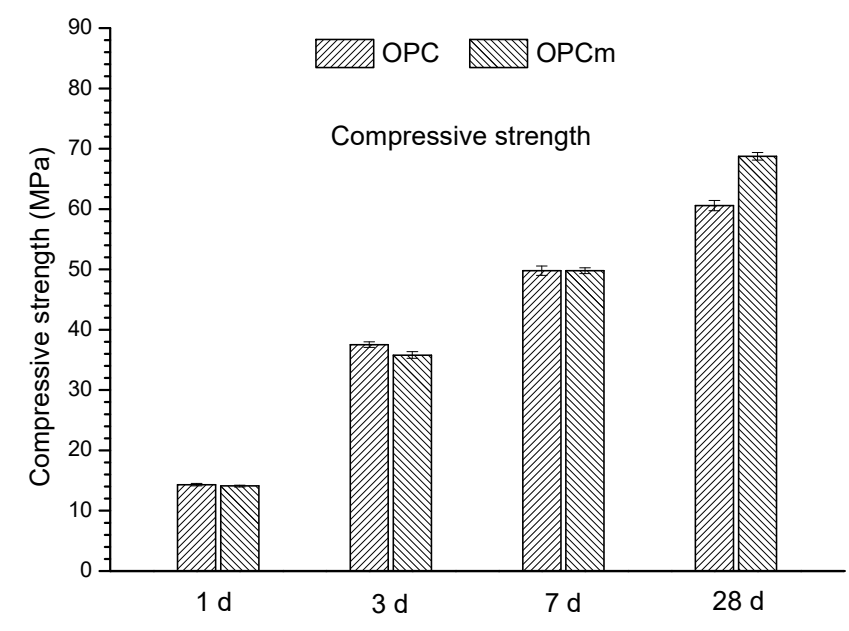

(a) Compressive strength

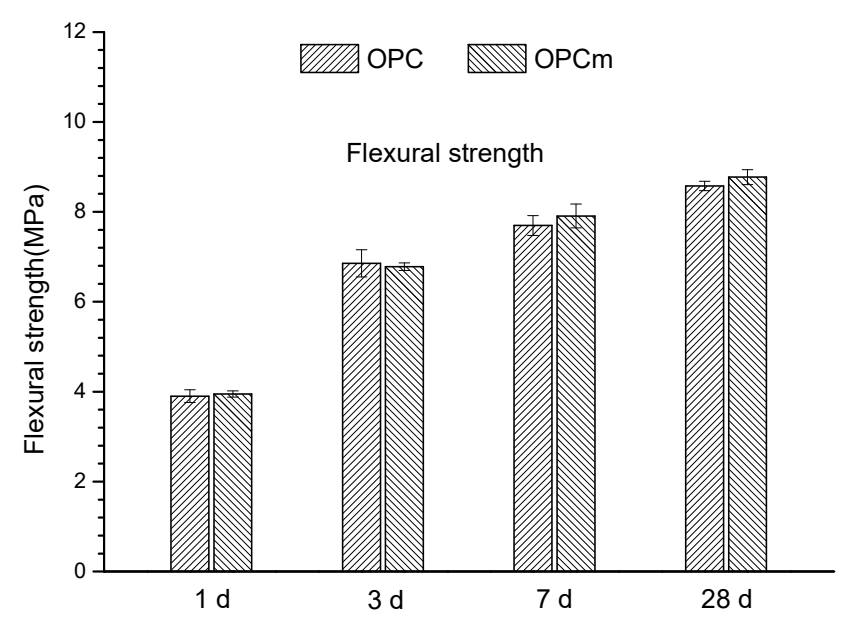

(b) Flexural strength

Figure 2. Compressive strength (a) and flexural strength (b) of mortar samples at different hydration ages. 


\subsection{Release amount of BTA Encapsulated in MCI from Mortar Sample}

Figure 3 presents the release percentage of the encapsulated BTA from the mortar sample after 3 days immersion in different SPS. Generally, the release percentage of BTA increased when $\mathrm{pH}$ of SPS was reduced. After immersed in SPS with $\mathrm{pH}$ of 12.7 (reference sample) and 12.4, the release percentage of the encapsulated BTA was very low, and only about $5 \%$ BTA was released from the mortar sample. A slightly higher release percentage of BTA $(10 \%)$ was observed when $\mathrm{pH}$ of SPS decreased to 11.5. In SPS with $\mathrm{pH}$ of 9, the release percentage of BTA was increased to about $25 \%$. When $\mathrm{pH}$ of SPS was further reduced to 7 , BTA presented a very high release percentage of $95 \%$. Therefore, $\mathrm{pH}$-triggered release performance of MCI was confirmed by the above experimental results. When $\mathrm{pH}$ was higher than 11.5, the released BTA content was very low, indicating that BTA steadily existed in mortar sample under high alkaline environment. When $\mathrm{pH}$ was lower than 9 , BTA was released with a significantly higher rate; specifically, when $\mathrm{pH}$ was reduced to 7 , almost all BTA reserved in MCI was released from the mortar sample.

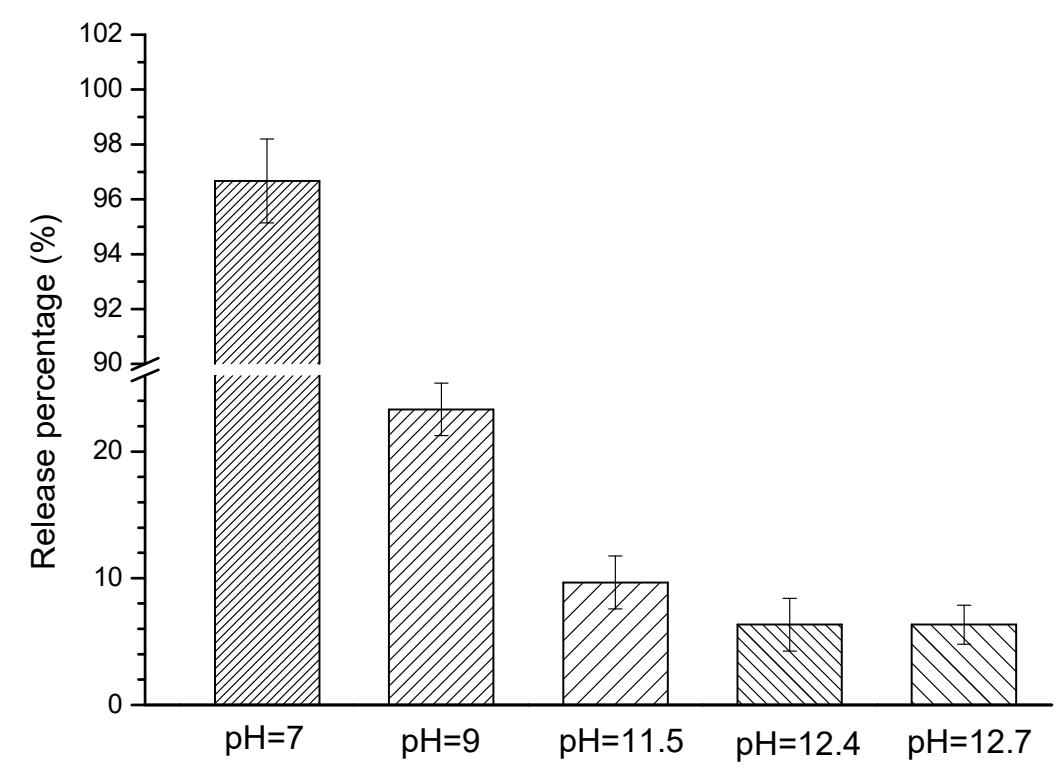

Figure 3. The release percentage of BTA reserved in MCI from mortar sample after immersed in SPS with different $\mathrm{pH}$ for 3 days.

\subsection{Morphology Alterations of the Mortar Samples}

Figure 4 shows SEM images of mortar samples immersed in different SPS for 3 days. For the reference sample (before immersion, Figure 4a), both sands with large dimensions (red circles in the image) and hydration products with small dimensions (blue circles in the image) were observed. In SPS with pH of 12.4 (Figure $4 \mathrm{~b}$ ), the above mentioned sands and hydration products also existed in mortar sample; however, the amount of hydration products was slightly lower, compared to the reference sample. Further, more needle shape hydration products were observed in the sample immersed in SPS with $\mathrm{pH}$ of 12.4. When $\mathrm{pH}$ of SPS was reduced to 7 (Figure 4c), the amount of hydration products was further reduced and mainly sands with large dimensions were observed in SEM image. This might be related to the dissolution of hydration products in SPS with low $\mathrm{pH}$ value, which will be further confirmed by XRF, XRD, FTIR and NMR analysis in Section 3.4. As a result, the hydration products exhibited more porous microstructure, compared to both reference sample and sample immersed in SPS with $\mathrm{pH}$ of 12.4, evidenced by the enlarged SEM images in Figure 4. The above morphology alterations of the mortar samples immersed in different SPS was attributed to the influence of $\mathrm{pH}$ on the composition of hydration products in mortar matrix, which is discussed further below. 


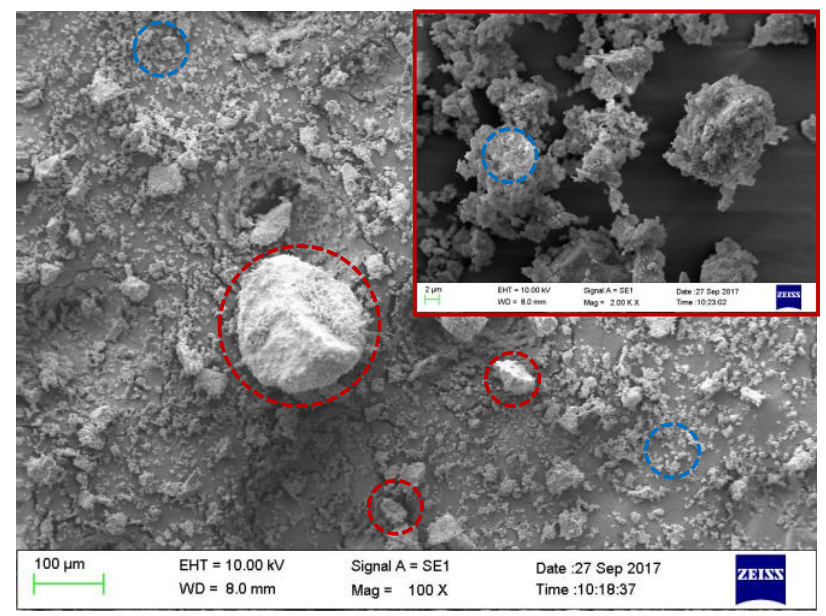

(a) Reference sample before immersion

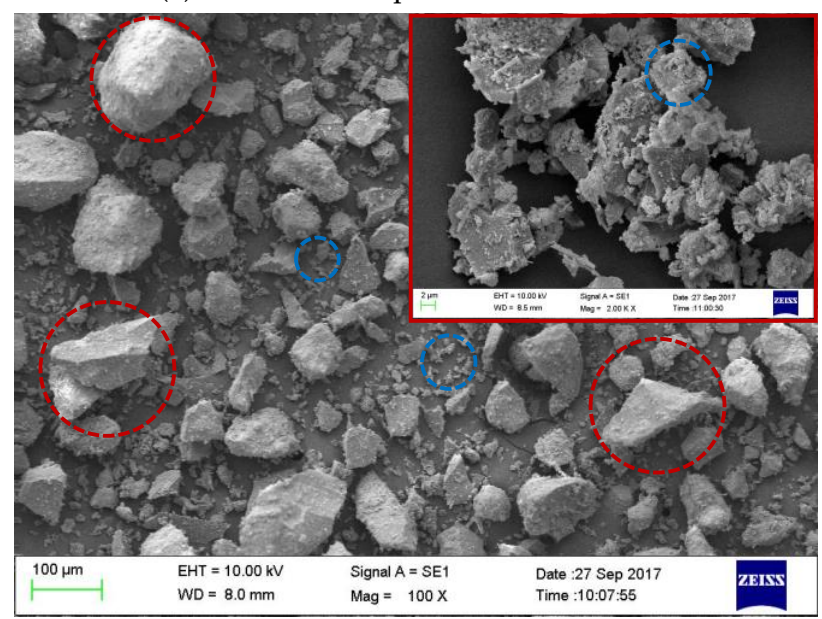

(c) $\mathrm{pH}=7$

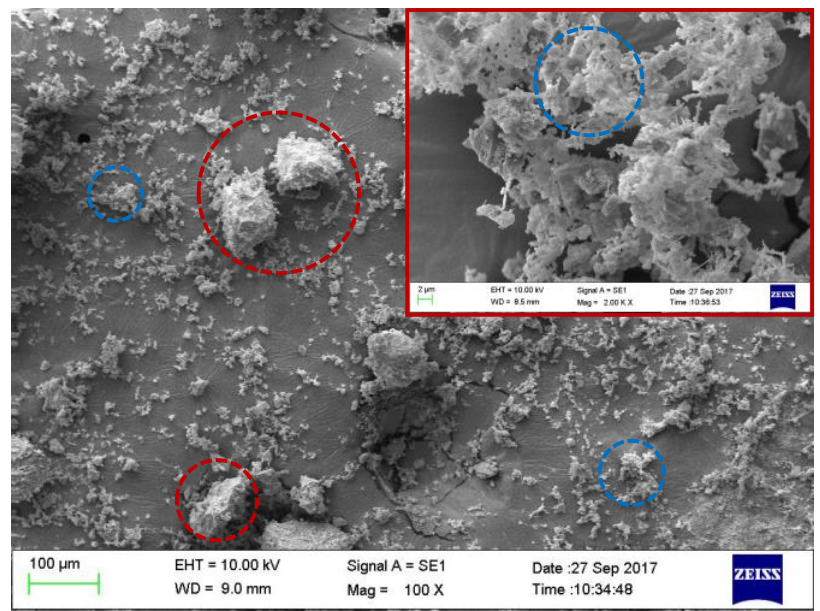

(b) $\mathrm{pH}=12.4$

Figure 4. SEM images of mortar samples after immersed in different SPS for 3 days: (a) Reference sample before immersion; (b) $\mathrm{pH}=12.4 ;$ (c) $\mathrm{pH}=7$.

3.4. Composition Alterations of the Hydration Products in Mortar Samples after Immersed in SPS

XRF results of the mortar sample after immersed in SPS with different $\mathrm{pH}$ for $3 \mathrm{~d}$ are presented in Table 4. For the reference sample, the main chemical composition of the mortar sample included $\mathrm{SiO}_{2}, \mathrm{CaO}, \mathrm{Al}_{2} \mathrm{O}_{3}$ and $\mathrm{Fe}_{2} \mathrm{O}_{3} . \mathrm{SiO}_{2}$ content was higher than $80 \mathrm{wt}$ \%, which was mainly corresponding to the sands in mortar sample. The chemical composition of the mortar sample after immersed in SPS with pH of 12.7 was very similar to the reference sample. After immersed in SPS with lower $\mathrm{pH}$ (i.e., $\mathrm{pH}$ of 12.4, 11.5, 9 and 7 ), the chemical composition of the mortar sample was altered: $\mathrm{SiO}_{2}$ content increased and $\mathrm{CaO}$ content decreased. Further, a lower $\mathrm{pH}$ of SPS resulted in a more significant alteration on the chemical composition of the mortar sample. For example, $\mathrm{SiO}_{2}$ and $\mathrm{CaO}$ content for the reference sample was $82.14 \mathrm{wt}$. \% and $12.26 \mathrm{wt}$. \%, respectively. However, after immersed in SPS with $\mathrm{pH}$ of $11.5, \mathrm{SiO}_{2}$ content increased to $89.02 \mathrm{wt}$ \% and $\mathrm{CaO}$ content was reduced to $6.04 \mathrm{wt}$. \%; after immersed in SPS with $\mathrm{pH}$ of 7, $\mathrm{SiO}_{2}$ content further increased to $91.97 \mathrm{wt}$. \% and $\mathrm{CaO}$ content was only $2.93 \mathrm{wt}$. \%. XRF results indicated that the immersion in SPS solution with low $\mathrm{pH}$ caused decomposition and dissolution of hydration products, leading to the increase of $\mathrm{SiO}_{2}$ content and reduction of $\mathrm{CaO}$ content in mortar sample. 
Table 4. Chemical composition (wt. \%) of the mortar sample after immersed in SPS with different $\mathrm{pH}$ for 3 days.

\begin{tabular}{ccccccc}
\hline Oxides & Reference & $\mathbf{p H}=\mathbf{1 2 . 7}$ & $\mathbf{p H}=\mathbf{1 2 . 4}$ & $\mathbf{p H}=\mathbf{1 1 . 5}$ & $\mathbf{p H}=\mathbf{9 . 0}$ & $\mathbf{p H}=\mathbf{7 . 0}$ \\
\hline $\mathrm{SiO}_{2}$ & 82.1 & 82.7 & 85.9 & 89.0 & 89.1 & 92.0 \\
$\mathrm{CaO}$ & 12.3 & 12.2 & 8.8 & 6.0 & 5.9 & 2.9 \\
$\mathrm{Al}_{2} \mathrm{O}_{3}$ & 2.9 & 2.7 & 2.9 & 3.0 & 3.0 & 2.9 \\
$\mathrm{Fe}_{2} \mathrm{O}_{3}$ & 1.1 & 1.0 & 1.1 & 1.0 & 1.0 & 1.0 \\
$\mathrm{SO}_{3}$ & 0.6 & 0.7 & 0.5 & 0.3 & 0.4 & 0.4 \\
$\mathrm{~K}_{2} \mathrm{O}$ & 0.6 & 0.6 & 0.5 & 0.5 & 0.6 & 0.6 \\
$\mathrm{TiO}_{2}$ & 0.1 & 0.1 & 0.1 & 0.1 & 0.0 & 0.0 \\
Others & 0.3 & 0.0 & 0.2 & 0.1 & 0.0 & 0.2 \\
\hline
\end{tabular}

Figure 5 presents XRD results of the mortar samples in different SPS at 3 days. Before immersion (the reference sample), the main crystal phases in the mortar sample were quartz $\left(\mathrm{SiO}_{2}\right)$, calcium hydroxide $(\mathrm{CH})$ and hemicarboaluminate hydrate $(\mathrm{Hc})$. When immersed in SPS with pH of 12.7, the crystal phases were quite similar to the reference sample. When immersed in SPS with $\mathrm{pH}$ of 12.4, the intensity of peaks corresponding to $\mathrm{CH}$ was significantly reduced; the crystal phases were mainly consisted of $\mathrm{SiO}_{2}$ and Hc. When immersed in SPS with $\mathrm{pH}$ of 11.5 , besides $\mathrm{CH}$, the peaks related to Hc also disappeared; the main crystal phase was only $\mathrm{SiO}_{2}$ corresponding to sands in the mortar sample. When the $\mathrm{pH}$ of SPS decreased to 9 , a new peak at $2 \theta 27^{\circ}$ appeared which was corresponding to CASH [22]; when $\mathrm{pH}$ of SPS was further reduced to 7, the peak intensity of CASH was increased. The above results indicated that the decrease on $\mathrm{pH}$ of SPS resulted in the dissolution of $\mathrm{CH}$ and $\mathrm{Hc}$ and generation of $\mathrm{CASH}$ gel.

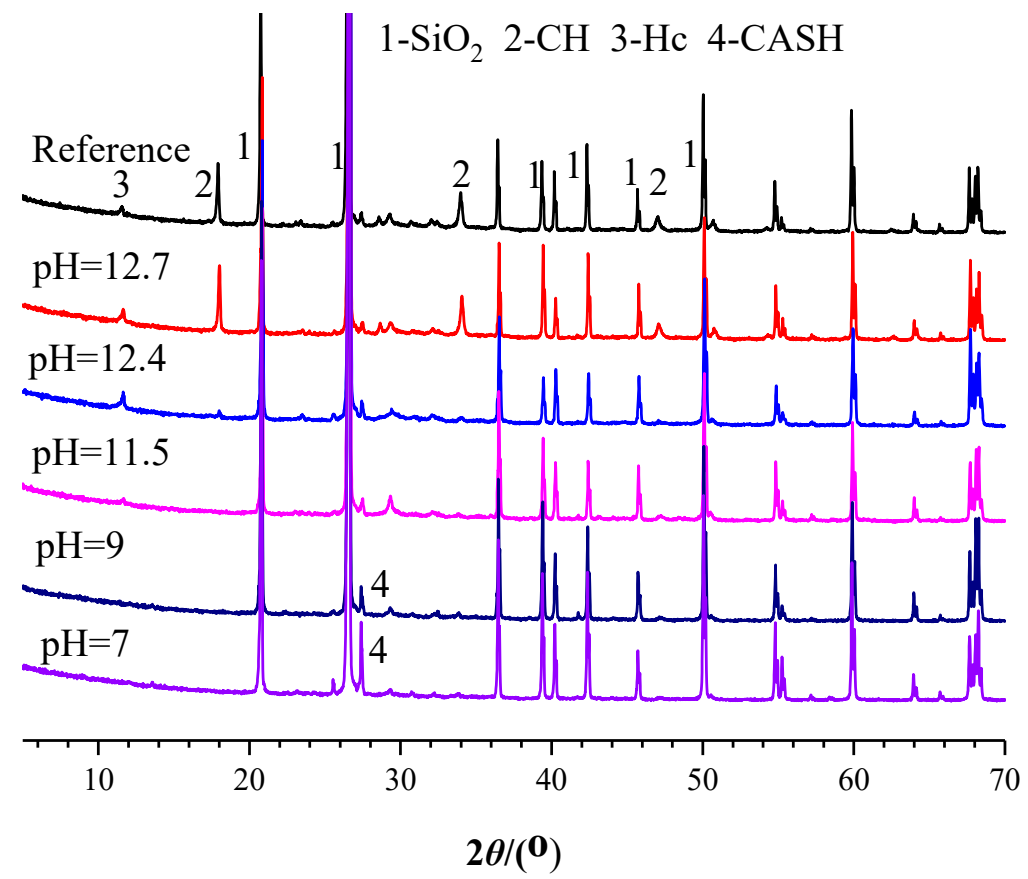

Figure 5. XRD patterns of the mortar samples after immersed in SPS with different $\mathrm{pH}$ for 3 days.

Figure 6 shows FTIR results of mortar samples after immersed in SPS with different $\mathrm{pH}$ for 3 days. Before immersion (reference sample), monosilicates $\left(\mathrm{Q}^{0}\right.$, at $\left.970 \mathrm{~cm}^{-1}\right)$, disilicates and chain end groups $\left(\mathrm{Q}^{1}\right.$, at $\left.812 \mathrm{~cm}^{-1}\right)$ and middle groups in chains $\left(\mathrm{Q}^{2}\right.$, at 967-1060 $\mathrm{cm}^{-1}$ ) [23-26] existed in the mortar sample; further, the infrared peaks of $\mathrm{C}=\mathrm{O}$ bond for $\mathrm{CO}_{3}{ }^{2-}$ (875 and 1400-1500 $\left.\mathrm{cm}^{-1}[25,27]\right)$ were also observed for the reference sample. FTIR results for the mortar samples immersed in SPS with $\mathrm{pH}$ of 12.7, 12.4 and 11.5 were quite similar to the reference samples before immersion, and the infrared peaks 
corresponding to $\mathrm{Q}^{1}, \mathrm{Q}^{2}$ and $\mathrm{C}=\mathrm{O}$ bond also existed. However, for the mortar samples immersed in SPS with $\mathrm{pH}$ of 9 and 7 , the infrared peak corresponding to $\mathrm{Q}^{1}$ was reduced and the infrared peak related to $\mathrm{Q}^{2}$ shifted to higher wavenumber, indicating the higher polymerization degree of silica chain for mortar samples in these solutions [28]. In addition, the infrared peaks for $\mathrm{C}=\mathrm{O}$ bond was shifted to lower wavenumber for the mortar samples immersed in SPS with $\mathrm{pH}$ of 11.5, 9 and 7, indicating that carbonate was decomposed when the mortar sample was immersed in SPS with $\mathrm{pH}<11.5$. Therefore, the $\mathrm{pH}$ threshold for the composition alteration of $\mathrm{CSH}$ was about 9. When $\mathrm{pH}$ was higher than 9, $\mathrm{CSH}$ was quite stable and its composition was not significant altered. When $\mathrm{pH}$ was below 9 , the polymerization degree of CSH increased, indicating that $\mathrm{CSH}$ was decomposed in mortar sample. Further, when $\mathrm{pH}$ was higher than 11.5 , the carbonates in the mortar sample was very stable; when $\mathrm{pH}$ was lower than 11.5 , carbonates became decomposed.

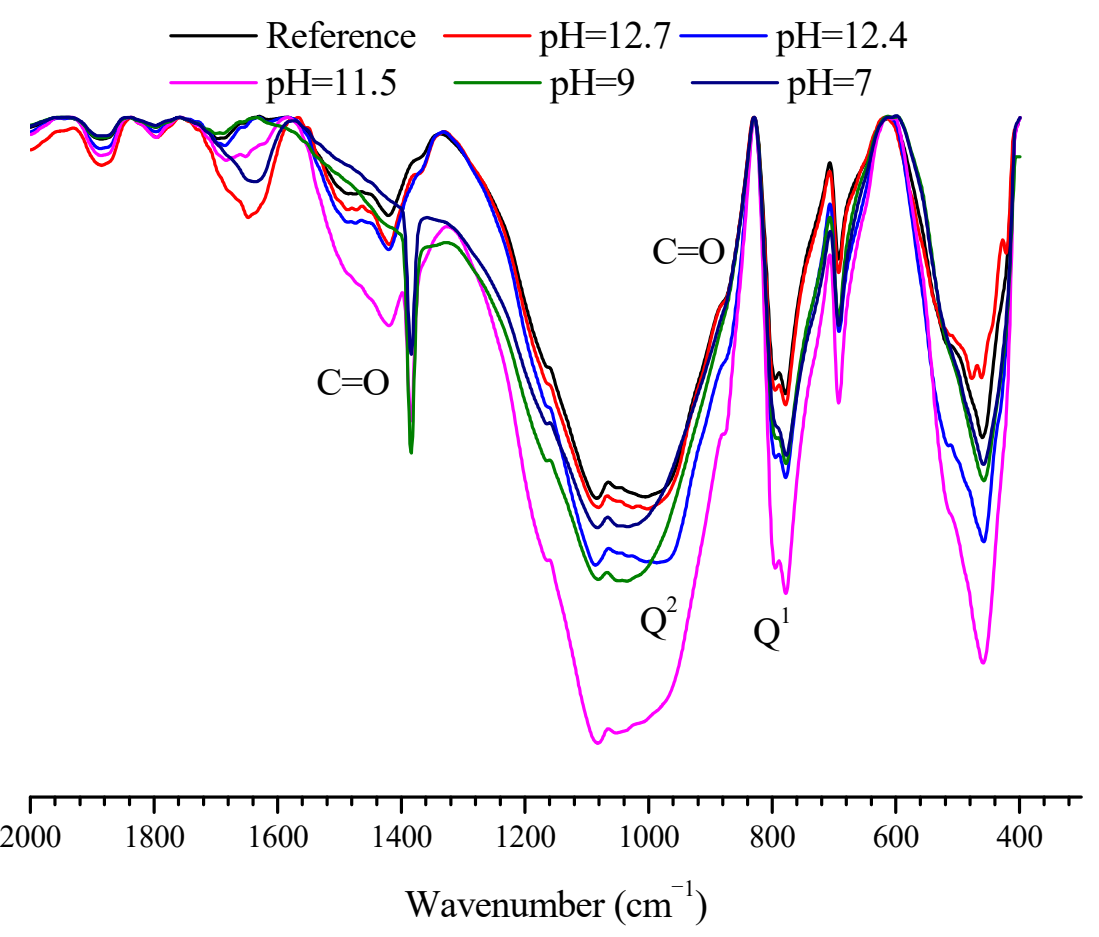

Figure 6. FTIR curves of the mortar samples after immersed in SPS with different $\mathrm{pH}$ for 3 days.

${ }^{29} \mathrm{Si}$ and ${ }^{27} \mathrm{Al}$ NMR spectra of the mortar sample after immersed in SPS with different $\mathrm{pH}$ for $3 \mathrm{~d}$ are presented in Figures 7 and 8 to further confirm the composition alterations of hydration products. Table 5 summarizes the chemical shifts of $Q^{0}, Q^{1}, Q^{2}, Q^{3}$ and $\mathrm{Q}^{4}$ in ${ }^{29} \mathrm{Si}$ NMR spectrum for cement-based materials [29]. Compared to the reference sample, when immersed in SPS with $\mathrm{pH}$ of 12.4, the intensity of the peaks corresponding to $Q^{0}$ was reduced and the intensity of the peaks related to $Q^{2}$ increased in ${ }^{29} \mathrm{Si} N M R$ spectra (Figure 7). When immersed in SPS with $\mathrm{pH}$ of 7 , the peaks corresponding to $\mathrm{Q}^{0}$ and $Q^{1}$ almost disappeared; the peak corresponding to $Q^{2}$ was significantly shifted to the right direction and the peaks related to $\mathrm{Q}^{4}$ were not obviously altered. ${ }^{29} \mathrm{Si}$ NMR results confirmed that CSH was decomposed in SPS with low $\mathrm{pH}$ value. Based on ${ }^{27} \mathrm{Al}$ NMR spectra (Figure 8), the intensity of the peaks corresponding to Al-O bond was not obviously altered for the sample immersed in SPS with $\mathrm{pH}$ of 12.4, compared to the reference sample. In SPS with $\mathrm{pH}$ of 7, the peaks corresponding to Al-O bond in AFt and AFm (about 13 ppm and 8ppm, respectively [29]) almost disappeared, indicating the decomposition of AFt and AFm; the intensity of the peak related to Al-O bond connecting with silica increased. Further, a new Al-O bond appeared at about 5 ppm which might be related to hydrous alumina gel [30], hydrated calcium aluminate [31,32] or aluminum hydroxide with low crystallinity [33]. 


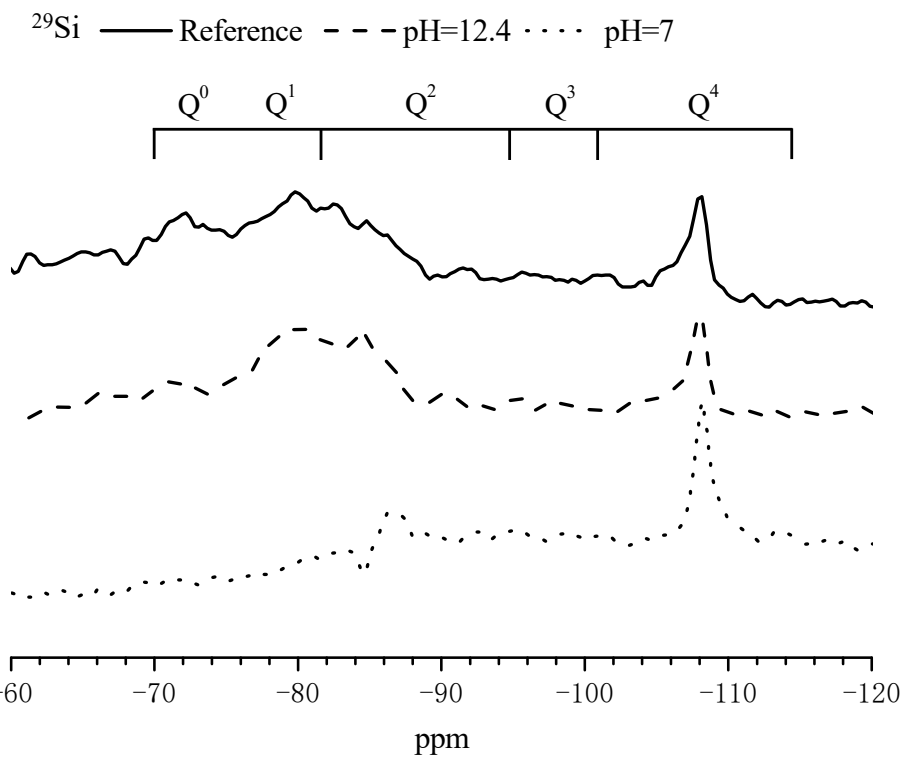

Figure 7. ${ }^{29}$ Si NMR spectra of the mortar samples after immersed in different SPS for 3 days.

${ }^{27} \mathrm{Al} \longrightarrow$ Reference - - - $\mathrm{pH}=12.4 \cdots \mathrm{pH}=7$

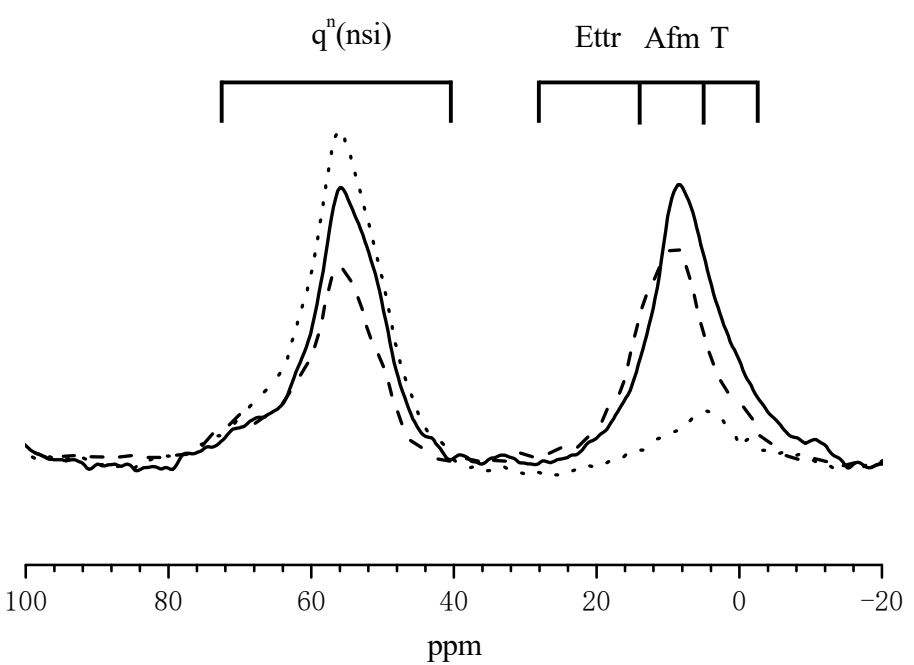

Figure 8. ${ }^{27} \mathrm{Al}$ NMR spectra of the mortar samples after immersed in different SPS for 3 days.

Table 5. Position of ${ }^{29} \mathrm{Si}$ NMR sites in hardened Portland cement paste [29].

\begin{tabular}{cc}
\hline Sites & Chemical Shift (ppm) \\
\hline $\mathrm{C}_{2} \mathrm{~S}-\mathrm{Q}^{0}$ & -71 \\
$\mathrm{C}_{3} \mathrm{~S}-\mathrm{Q}^{0}$ & -69 to -73 \\
$\mathrm{CASH}-\mathrm{Q}^{1}$ & -79 \\
$\mathrm{CASH}-\mathrm{Q}^{2}(1 \mathrm{Al})$ & -82 \\
$\mathrm{CASH}-\mathrm{Q}^{2}$ & -85 \\
$\mathrm{Q}^{2}(1 \mathrm{Al})$ & -86 \\
$\mathrm{Q}^{2}$ & -92 \\
$\mathrm{Q}^{3}(1 \mathrm{Al})$ & -95 \\
$\mathrm{Q}^{3}$ & -101 \\
$\mathrm{Q}^{4}(1 \mathrm{Al})$ & -104 \\
$\mathrm{Q}^{4}$ & -110 \\
\hline
\end{tabular}




\subsection{Corrosion Inhibition Effect of MCI on the Reinforcement Embedded in Mortar}

3.5.1. Influence of MCI on the Electrochemical Behavior of the Reinforcement Embedded in Mortar

Open circuit potential (OCP) of the reinforcement embedded in mortar samples is presented in Figure 9. OCP of both the reference and MCI-containing samples exhibited very positive value (in the range of $-110 \mathrm{mV}$ to $-212 \mathrm{mV}$ ) at early immersion age; OCP of MCI-containing sample was slightly more negative than the reference sample. OCP of all samples were more positive than $-250 \mathrm{mV}$ (OCP threshold for passivity of the reinforcement [34]), indicating that the reinforcement embedded in mortar was in passive state both for the reference and MCI-containing samples at early immersion age. For the reference sample, OCP of the reinforcement was shifted to more negative than $-400 \mathrm{mV}$ after immersed for $80 \mathrm{~d}$, indicating corrosion initiation of the reinforcement at this moment. However, MCI-containing sample still presented OCP of about $-160 \mathrm{mV}$ at the same time interval. For MCI-containing sample, the time for negative OCP shift of the reinforcement was prolonged to about 113 days and its potential was negatively shifted to about $-500 \mathrm{mV}$ while OCP of the reference sample was about $-460 \mathrm{mV}$. Therefore, corrosion initiation of the reinforcing steel embedded in mortar was significantly retarded in the presence of $\mathrm{MCI}$. After corrosion initiation, $\mathrm{OCP}$ of MCI-containing sample was more negative than the reference sample (about $40-120 \mathrm{mV}$ difference); further, positive OCP shift was observed for MCI-containing sample at the immersion age of about $126 \mathrm{~d}$. The above positive OCP shift for MCI-containing sample might be related to self-repairing of the reinforcement surface due to the release of BTA from MCI at the corrosion locations, which will be discussed in detail further below.

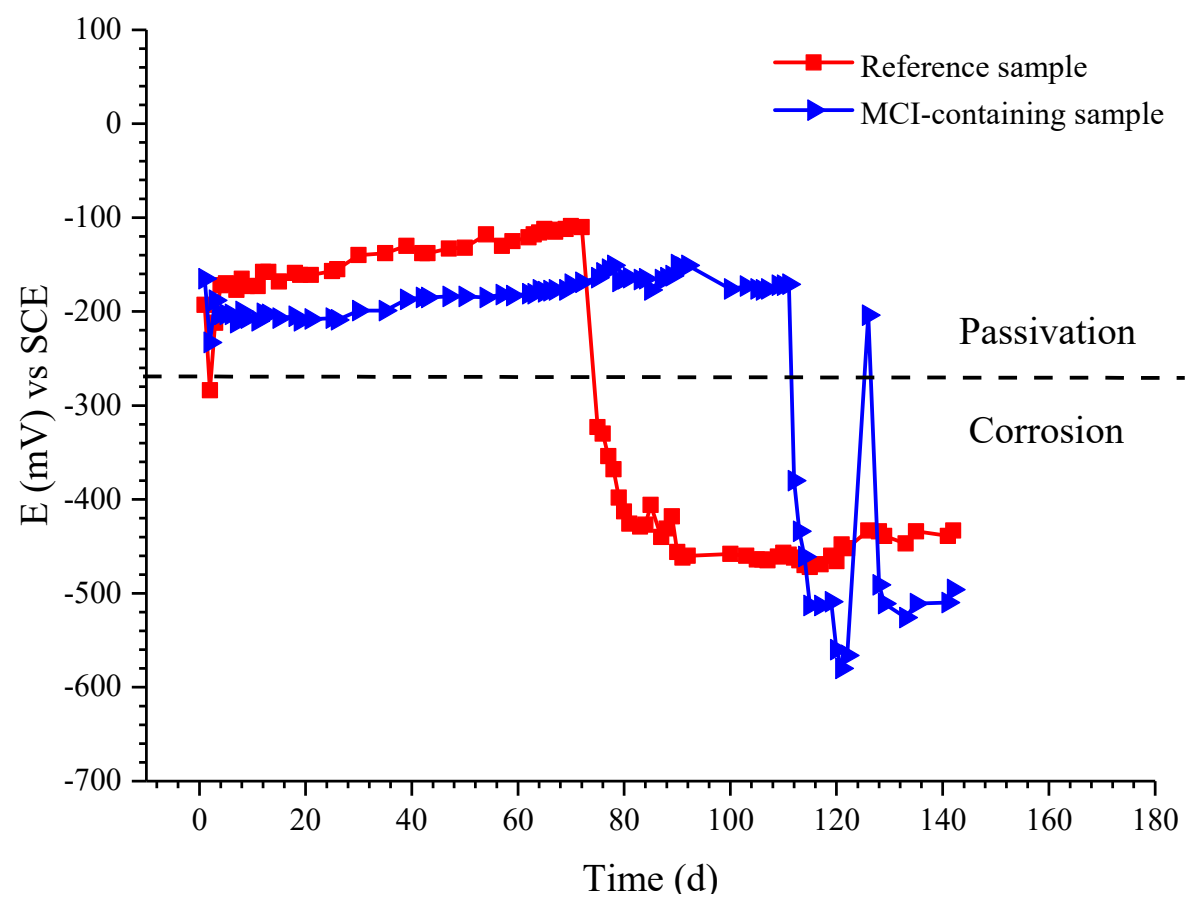

Figure 9. Open circuit potential of the reinforced mortar immersed in $3.5 \mathrm{wt}$. \% $\mathrm{NaCl}$ solution.

PD curves of the reinforced mortar samples are shown in Figure 10. At early immersion ages (i.e., 21 days and 72 days, as shown in Figure 10a), PD curves for the reference and MCI-containing samples were almost identical; the reference sample exhibited slightly more positive corrosion potential $\left(\mathrm{E}_{\mathrm{corr}}\right)$ and lower anodic current density, compared to MCI-containing sample. The above results indicated that MCI didn't present pronounced effect on the electrochemical behavior of the embedded reinforcement before corrosion initiation. At $85 \mathrm{~d}$ and $92 \mathrm{~d}$ (Figure 10b), based on OCP results in Figure 9, corrosion damage for the reference sample was initiated; however, MCI-containing sample was 
still in passive state. As a result, $\mathrm{E}_{\text {corr }}$ for MCI-containing sample was dramatically more positive, compared to the reference sample; the anode current density for MCI-containing sample was also significantly lower than the reference sample. MCI exhibited efficient corrosion inhibition effect on the reinforcement embedded in mortar during this immersion stage. At late immersion ages of $115 \mathrm{~d}$ and $135 \mathrm{~d}$ (Figure 10c), both the reference and MCI-containing samples exhibited very negative $\mathrm{E}_{\text {corr }}$ value, which was corresponding to corrosion damage of the embedded reinforcement. At this stage, $\mathrm{E}_{\text {corr }}$ for MCI-containing sample was more negative, compared to the reference sample. However, the anode and cathode current densities for MCI-containing sample were lower than the reference sample, indicating that $\mathrm{MCI}$ was the mixed type corrosion inhibitor [35] and still exhibited corrosion inhibition effect on the embedded reinforcement after corrosion initiation.

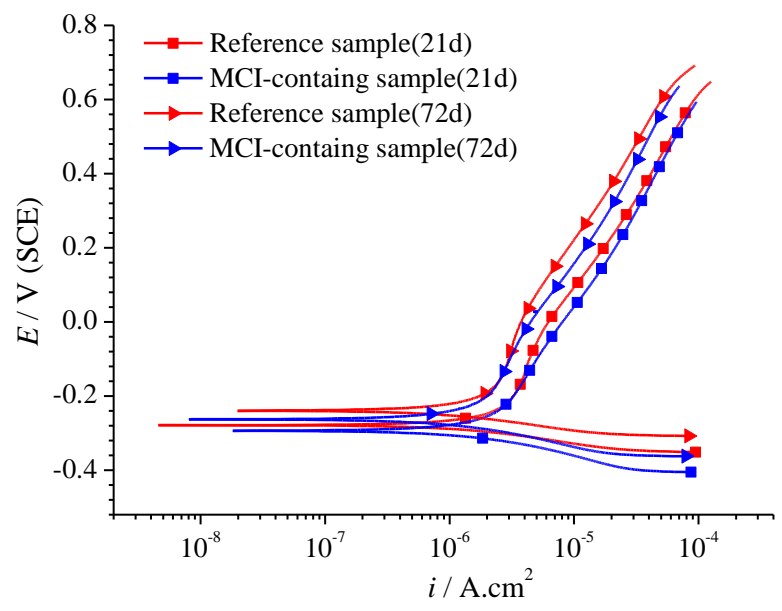

(a) $21 \mathrm{~d}$ and $72 \mathrm{~d}$

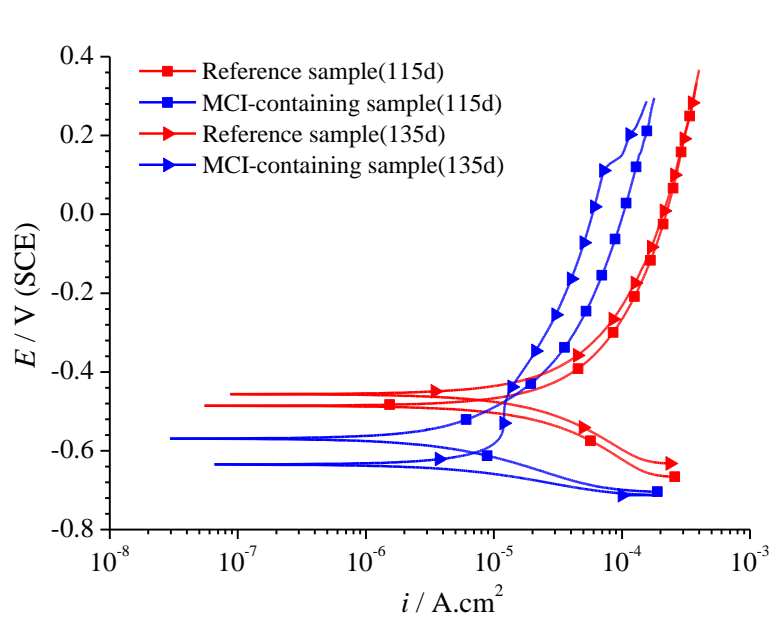

(c) $115 \mathrm{~d}$ and $135 \mathrm{~d}$

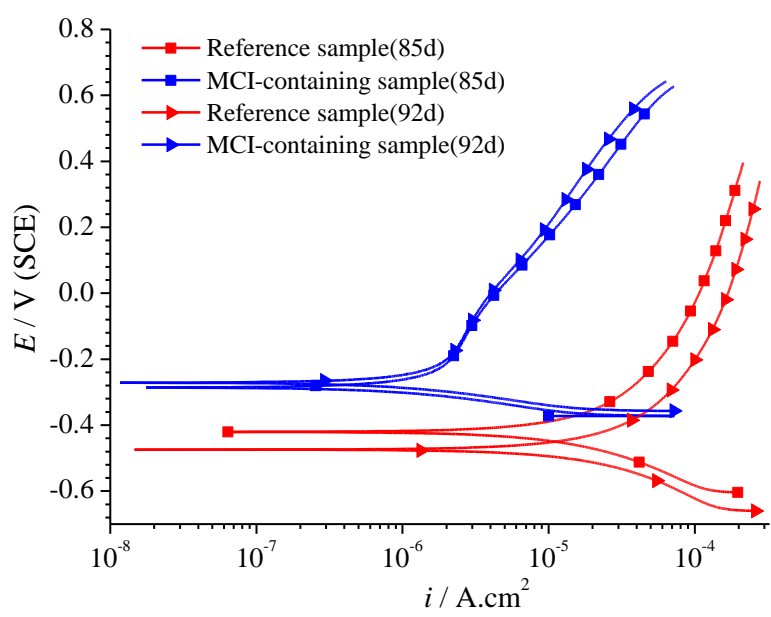

(b) $85 \mathrm{~d}$ and $92 \mathrm{~d}$

Figure 10. Potentio-dynamic polarization curves of reinforced mortar in $3.5 \% \mathrm{NaCl}$ solution at different immersion ages: (a) $21 \mathrm{~d}$ and $72 \mathrm{~d}$; (b) $85 \mathrm{~d}$ and 92d; (c) $115 \mathrm{~d}$ and $135 \mathrm{~d}$.

Corrosion current densities $\left(\mathrm{I}_{\text {corr }}\right)$ for different samples calculated based on PD curves [36] are presented in Figure 11. At early immersion ages (i.e., $21 \mathrm{~d}$ and $72 \mathrm{~d}$ ), the reinforcement for all samples was in passive state, thus exhibiting very low $\mathrm{I}_{\text {corr }}$ (in the range of 0.042 to $0.061 \mu \mathrm{A} \cdot \mathrm{cm}^{-2}$ ). MCI didn't present obvious influence on $\mathrm{I}_{\text {corr }}$. At $85 \mathrm{~d}$ and $92 \mathrm{~d}, \mathrm{I}_{\text {corr }}$ for the reference sample was dramatically increased (in the range of 0.484 to $0.497 \mu \mathrm{A} \cdot \mathrm{cm}^{-2}$ ); $\mathrm{I}_{\text {corr }}$ for MCI-containing sample was still maintained at very low level (in the range of 0.0416 to $0.0443 \mu \mathrm{A} \cdot \mathrm{cm}^{-2}$ ) because the reinforcement was still in passive state. At late immersion 
age (i.e., $115 \mathrm{~d}$ and $135 \mathrm{~d}$ ), because corrosion damage for MCI-containing sample was also initiated, $\mathrm{I}_{\text {corr }}$ was slightly increased (in the range of 0.114 to $0.169 \mu \mathrm{A} \cdot \mathrm{cm}^{-2}$ ). However, $\mathrm{I}_{\text {corr }}$ for MCI-containing sample was still significantly lower, compared to the reference sample.

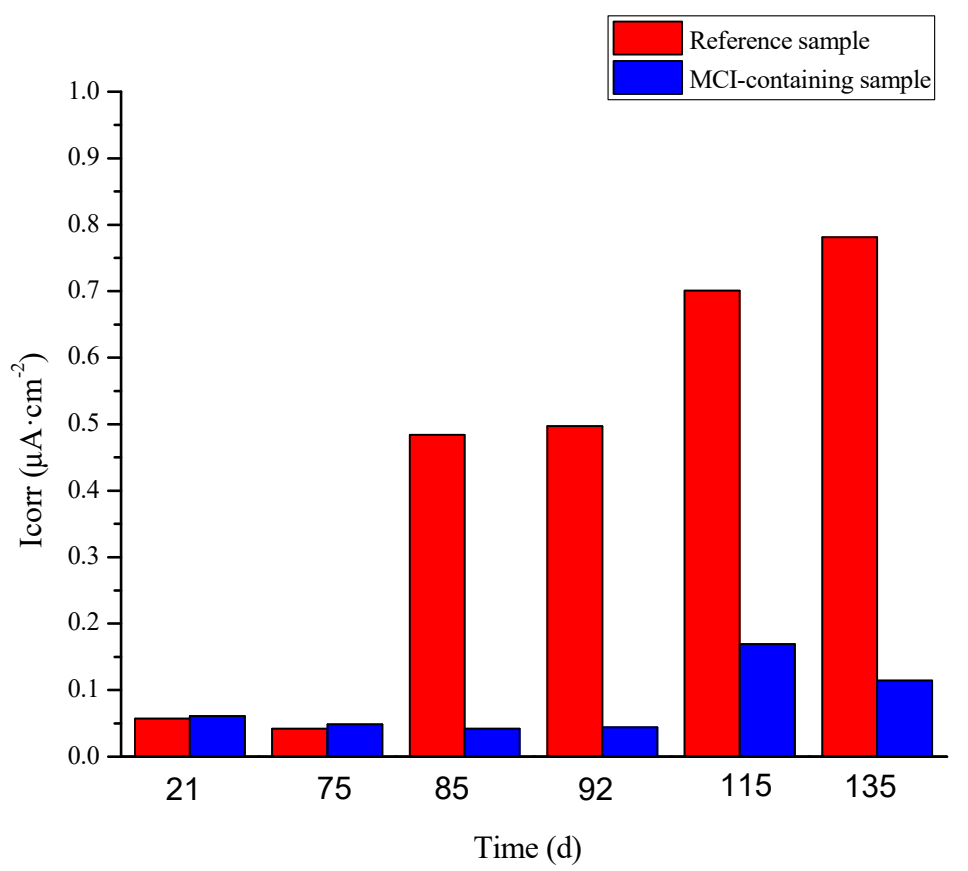

Figure 11. Corrosion current density of the embedded reinforcement calculated based on PD curves.

\subsubsection{Influence of MCI on the Morphology and Composition of Corrosion Products}

Figure 12 shows SEM images at the reinforcement/mortar interface after 135 days. Severe accumulation of corrosion products was observed for the reference MCI-free sample, evidenced by a thickness of about $120 \mu \mathrm{m}$ (Figure 12a). In the presence of MCI, the thickness of the formed corrosion products was dramatically reduced to about $20 \mu \mathrm{m}$. Figure 13 presents SEM images of different samples after 135 days. Corrosion products with porous microstructure and large size were observed for MCI-free sample (Figure 13a). For MCIcontaining sample (Figure 13b), much less corrosion products with smaller size and more compact microstructure was observed on the reinforcement surface.

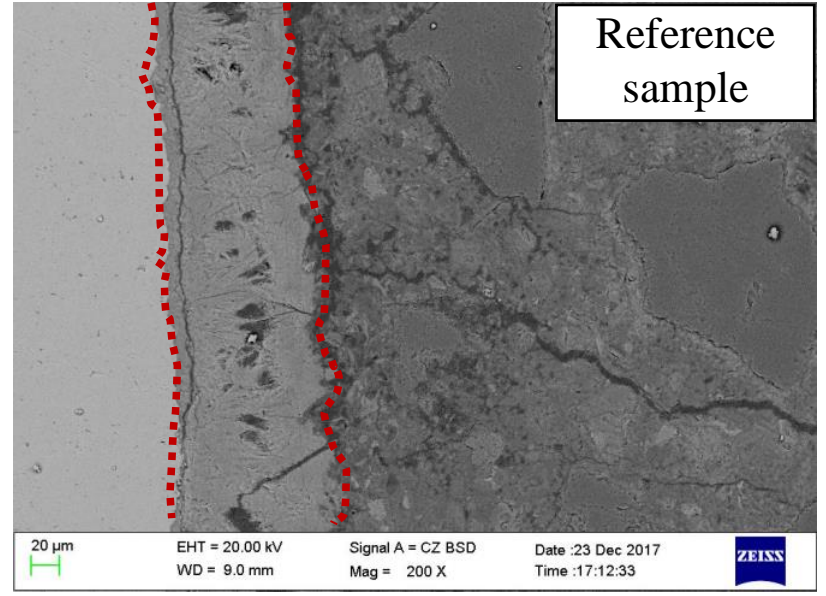

(a) Reference sample

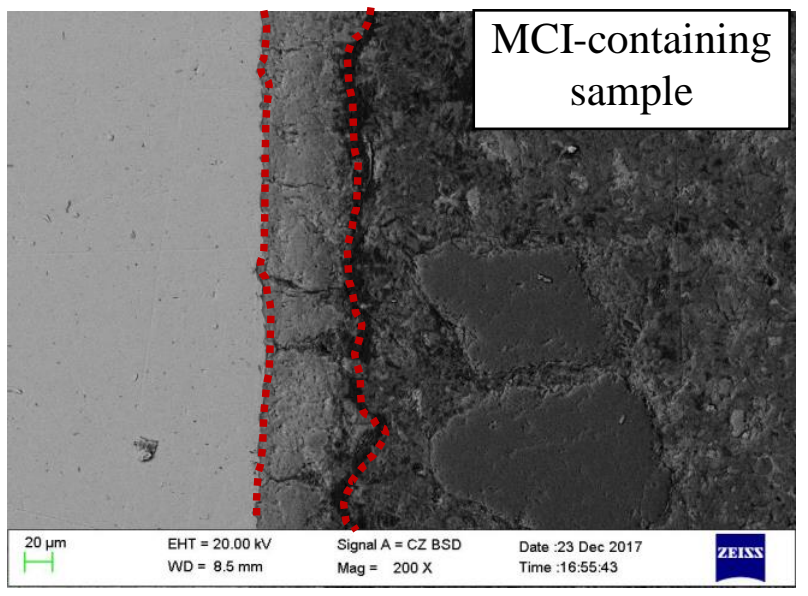

(b) MCI-containing sample

Figure 12. SEM images at the reinforcement/mortar interface after the sample was immersed in $3.5 \% \mathrm{NaCl}$ solution for 135 days: (a) Reference sample; (b) MCI-containing sample. 


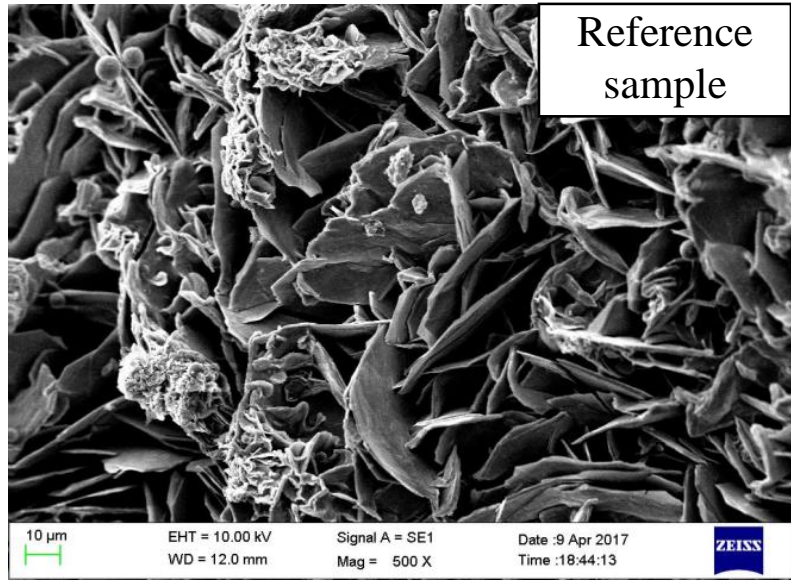

(a) Reference sample

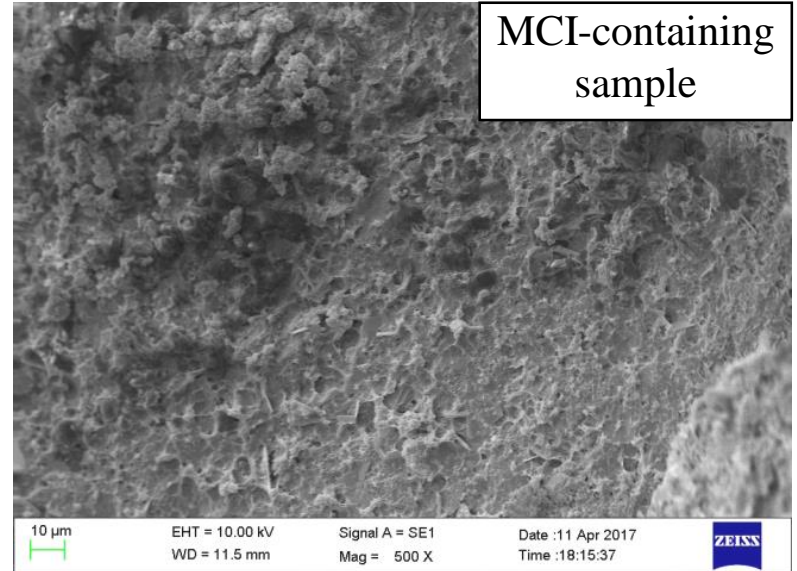

(b) MCI-containing sample

Figure 13. SEM images of the reinforcement surface for different samples after immersed in $\mathrm{NaCl}$ solution for 135 days: (a) Reference sample; (b) MCI-containing sample.

Raman spectra of the formed corrosion products for different samples after immersed in $\mathrm{NaCl}$ solution for 135 days are presented in Figure 14. For the reference sample, the mainly formed corrosion products were the mixtures of $\alpha-\mathrm{Fe}_{2} \mathrm{O}_{3}$ and $\gamma-\mathrm{FeOOH}$ [37]. The above corrosion products exhibited porous microstructure and large volume expansion, leading to more serious corrosion damage of the steel bar [38]. MCI significantly halted the formation of corrosion products, evidenced by the dramatically lower peak intensity in Raman spectrum for MCI-containing sample. The main corrosion product for MCIcontaining sample was $\gamma-\mathrm{Fe}_{2} \mathrm{O}_{3}$ with compact structure [39]. The above surface analysis results indicated that MCI significantly retarded corrosion product propagation on the surface of the reinforcement embedded in mortar sample.

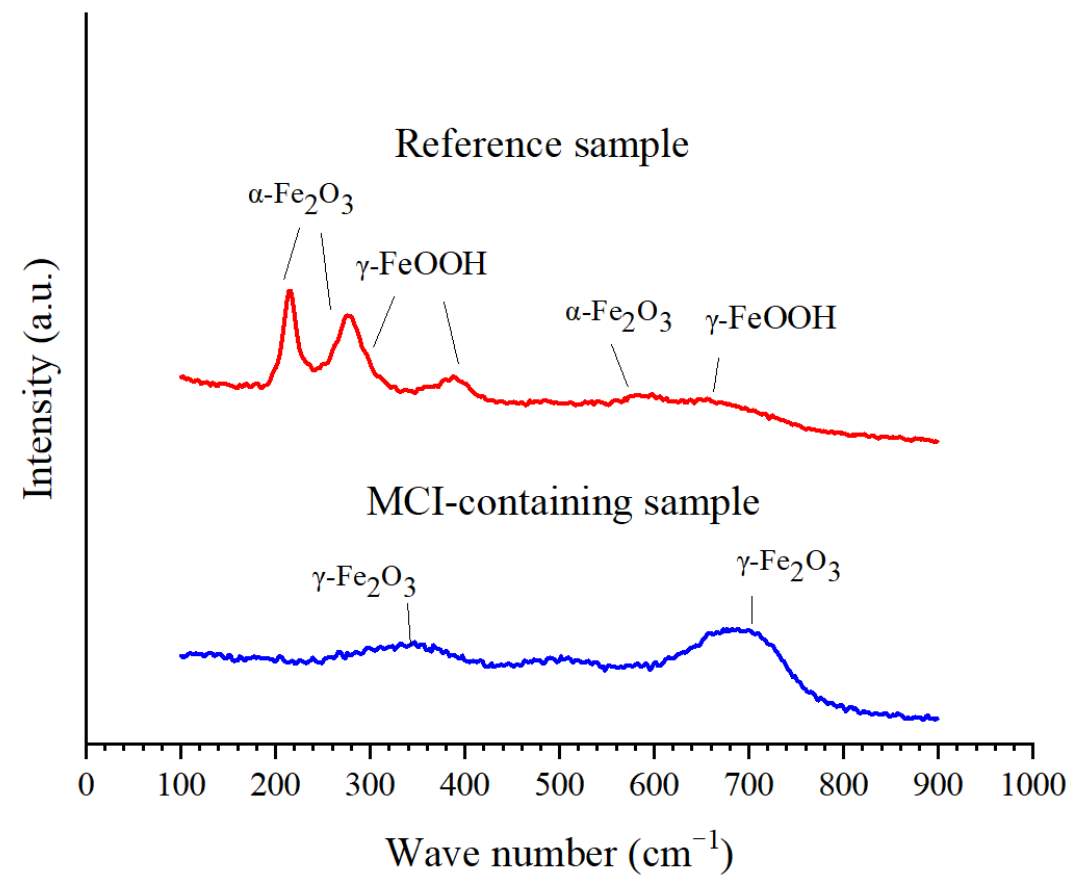

Figure 14. Raman spectrum of the formed corrosion products for different samples after immersed in $3.5 \% \mathrm{NaCl}$ solution for 135 days.

\section{Discussion}

It was mentioned in Introduction section that our previous study [19] proved the $\mathrm{pH}$ sensitivity for the release of BTA encapsulated in MCI in simulated cement pore solution. 
In SPS with pH of 13, BTA was steadily loaded in MCI; when pH of SPS decreased to 11, 5 times more BTA was released from MCI. The pronounced $\mathrm{pH}$ sensitivity for BTA release in SPS was possibly related to the hindered diffusion of BTA resulted from the generation of Na rich film around MCI and agglomerates of MCI under high alkaline environment $(\mathrm{pH}=13)$. In this present study, MCI also exhibited high $\mathrm{pH}$ sensitivity in the mortar sample (Figure 3). However, due to the small size and hydrophilic characteristic, MCI was covered by hydration products in mortar sample. Therefore, the release behavior of BTA in mortar sample was different from SPS, which was closely related to the composition/microstructure alterations of the hydration products under different $\mathrm{pH}$ environment (Figure 15).

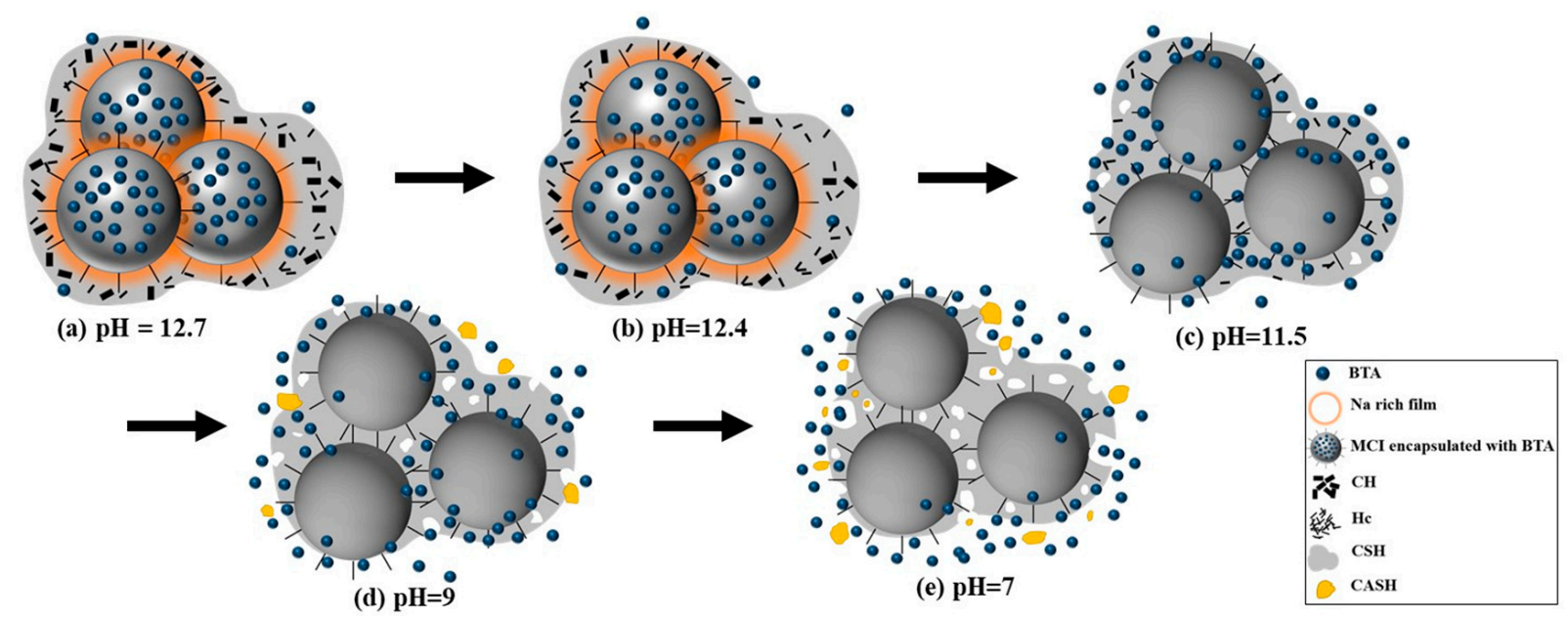

Figure 15. Release process of the reserved BTA in mortar sample under different $\mathrm{pH}$ environment: $(\mathbf{a}) \mathrm{pH}=12.7$; (b) $\mathrm{pH}=12.4 ;$ (c) $\mathrm{pH}=11.5 ;$ (d) $\mathrm{pH}=9$; (e) $\mathrm{pH}=7$.

When mortar sample was immersed in SPS with $\mathrm{pH}$ of $12.7\left(\mathrm{pH}\right.$ of saturated $\mathrm{Ca}(\mathrm{OH})_{2}$ solution [40]), most hydration products were quite stable under this high alkaline environment (Figures 5 and 6). When immersed in SPS with $\mathrm{pH}$ of 12.4, $\mathrm{CH}$ dissolved because $\mathrm{pH}$ of SPS was below the $\mathrm{pH}$ of saturated calcium hydroxide solution [40]. The decomposition and dissolution of other hydration products were not relevant (Figures 5-8). Under the above high alkaline environment, a very low release rate was relevant for BTA from MCI, due to the previously reported retarded diffusion of BTA under high alkaline environment [19]. Since crystal hydration products, i.e., $\mathrm{CH}$ and AFt normally exhibited plate-like or needle-like shape [41], it was supposed that MCI was mainly covered by CSH in mortar sample, thus the dissolution of $\mathrm{CH}$ didn't obviously influence the diffusion of BTA in the mortar sample. When $\mathrm{pH}$ of SPS was higher than 12.4, CSH stably existed in mortar sample, evidenced by FTIR and NMR results (Figures 6 and 7). The stable CSH gel surrounding MCI further halted the diffusion of BTA in mortar sample. As a result, due to the combined effects of both high alkaline environment and barrier of the surrounded stable CSH gel, the released BTA amount from mortar sample was quite low (only about 5\%) in SPS with $\mathrm{pH}>12.4$ (Figures 3 and $15 \mathrm{a}, \mathrm{b}$ ).

When immersed in SPS with pH of 11.5, the reserved BTA was rapidly released from $\mathrm{MCI}$, because $\mathrm{MCI}$ agglomerates and Na-rich film were not relevant under this $\mathrm{pH}$ environment according to our previous study [19]. However, CSH gel still stably existed in the mortar sample (Figure 6) because this $\mathrm{pH}$ value was higher than the critical $\mathrm{pH}$ for $\mathrm{CSH}$ decomposition $(\mathrm{pH}=9$ [40]). Therefore, BTA release rate was also very slow when mortar sample was immersed in SPS with $\mathrm{pH}$ of 11.5. In addition to $\mathrm{CH}$, Hc (resulted from the carbonation of AFt) also decomposed in SPS with $\mathrm{pH}$ of 11.5 (Figure 5), leading to more porous hydration products around MCI. As a result, slightly more BTA $(10 \%)$ was released from mortar into SPS with $\mathrm{pH}$ of 11.5 (Figure 15c), compared to SPS with $\mathrm{pH}$ of 12.7 and 12.4. This was quite different from BTA release behavior in SPS, in which the 
released BTA amount from MCI was increased by 5 times in SPS with $\mathrm{pH}<11$ [19]. When the mortar sample was immersed in SPS with $\mathrm{pH}$ of 9, $\mathrm{CH}$ and Hc were almost dissolved and decomposed in the mortar sample (Figure 5). Furthermore, CSH gel was also partially decomposed, evidenced by FTIR results (Figure 6). Even though a small amount of CASH formed by the reaction between silicate gel and hydrated calcium aluminate, evidenced by FTIR and ${ }^{27} \mathrm{Al}$ NMR spectra (Figures 6 and 8), the partial decomposition of CSH still led to more porous microstructure and reduced barrier effect of CSH around MCI. As a result, the release amount of BTA from the mortar sample was increased to $25 \%$ when immersed in SPS with $\mathrm{pH}$ of 9 (Figure 15d). When $\mathrm{pH}$ of SPS was further reduced to 7, more CSH in the immersed mortar sample was decomposed, evidenced by SEM observation, FTIR and NMR results (Figures 4c, 6 and 7). Therefore, the barrier effect of CSH around MCI was very limited, and most BTA (more than 95\%) was released from the mortar sample immersed in SPS with $\mathrm{pH}$ of 7 (Figure 15e).

In this study, hydration products indeed significantly affected the release behavior of BTA loaded in MCI, leading to a more complicated BTA release process in mortar sample. However, the rapid release of BTA can be also achieved in mortar sample by $\mathrm{pH}$ drop which would happen at corrosion sites on the reinforcing steel. In reinforced mortar, before corrosion initiation of the reinforcing steel, BTA was stably reserved in MCI due to the high alkalinity in mortar. As a result, the corrosion resistance was not obviously influenced by MCI (Figures 10a and 11). However, the admixed MCI adsorbed on the surface of steel bar, hindering $\mathrm{O}_{2}$ and chloride diffusions and subsequently leading to slightly negative shift of $\mathrm{OCP}$ and $\mathrm{E}_{\mathrm{corr}}$ at this stage and retarded corrosion initiation for MCI-containing sample (Figures 9 and 10b). After corrosion initiation, BTA reserved in MCI was rapidly released because of $\mathrm{pH}$ drop at corrosion sites on the reinforcing steel surface. The released BTA together with the empty MCI acted as the barrier, halting both anode and cathode reactions during the corrosion damage process, thus inhibiting corrosion damage of the reinforcing steel embedded in mortar after corrosion initiation (Figures 10c and 11). The inhibition effect of MCI was also evidenced by the pronounced positive OCP shift (about $400 \mathrm{mV}$ ) for MCI-containing sample after $126 \mathrm{~d}$ immersion (as shown in Figure 9). The corrosion inhibition effect of $\mathrm{MCI}$ on reinforced mortar reported in this present study confirms that the rapid release of BTA in the mortar sample caused by $\mathrm{pH}$ drop makes the prepared MCI possesses a high potential application on smart corrosion protection, increasing the corrosion resistance of reinforced concrete. The corrosion inhibition effect and related mechanisms of MCI on reinforced mortar was also extensively investigated and will be separately reported elsewhere.

\section{Conclusions}

The release behavior of the reserved BTA in $\mathrm{MCI}$ exhibited pronounced $\mathrm{pH}$ sensitivity in mortar sample in this paper. Under high $\mathrm{pH}$ environment $\mathrm{pH}>12.4)$, only about $5 \%$ reserved BTA was released from the mortar sample; when $\mathrm{pH}$ was reduced to 11.5 and 9, the release amount of BTA from the mortar sample was increased to about $10 \%$ and $25 \%$, respectively. Under low $\mathrm{pH}$ environment $(\mathrm{pH}=7$ ), most BTA (more than 95\%) was released from the mortar sample.

The composition alterations of the hydration products in the mortar sample were also observed when immersed in SPS with different $\mathrm{pH}$ value. When the $\mathrm{pH}$ of SPS decreased, $\mathrm{CH}$ and Hc were first decomposed; when the $\mathrm{pH}$ of SPS was lower than 9, CSH in mortar sample became decompose and a small amount of CASH formed. The above composition alterations of the mortar sample resulted in more porous hydration products surrounding $\mathrm{MCI}$, leading to faster BTA release from the mortar sample under low $\mathrm{pH}$ environment.

Due to the smart release of BTA in mortar sample, MCI efficiently retarded corrosion initiation of reinforced mortar. Further, the released BTA significantly reduced corrosion product accumulation, thus dramatically increased corrosion resistance of the reinforcement after corrosion initiation. 
Author Contributions: Conceptualization, J.H. (Jie Hu); methodology, Y.Z. and J.H. (Jie Hu); software, Y.Z. and J.H. (Jinzhen Huang); validation, Y.Z. and J.H. (Jinzhen Huang); formal analysis, Y.Z. and J.H. (Jinzhen Huang); investigation, Y.Z. and J.H. (Jinzhen Huang); resources, J.H. (Jie Hu), J.W. and Q.Y.; data curation, H.H. and J.H. (Jie Hu); writing — original draft preparation, J.H. (Jinzhen Huang); writing-review and editing, J.H. (Jinzhen Huang), J.H. (Jie Hu), Y.M. and H.H.; visualization, J.H. (Jinzhen Huang) and J.H. (Jie Hu); supervision, J.H. (Jie Hu), H.H. and J.W.; project administration, J.H. (Jie Hu) and Q.Y.; funding acquisition, J.H. (Jie Hu) and Y.M.. All authors have read and agreed to the published version of the manuscript.

Funding: This research was funded by National Key R\&D Program of China (No. 2017YFB0309904), National Natural Science Foundation of China (No. U2001225), Guangdong International Science and Technology Project (No. 2020A0505100006) and Pearl River S\&T Nova Program of Guangzhou (No. 201806010188). Their financial supports are gratefully acknowledged.

Institutional Review Board Statement: Not applicable.

Informed Consent Statement: Not applicable.

Data Availability Statement: Data available on request due to restrictions e.g., privacy or ethical.

Conflicts of Interest: The funders had no role in the design of the study; in the collection, analyses or interpretation of data; in the writing of the manuscript or in the decision to publish the results.

\section{References}

1. Stefanoni, M.; Angst, U.; Elsener, B. Corrosion rate of carbon steel in carbonated concrete-A critical review. Cem. Concr. Res. 2018, 103, 35-48. [CrossRef]

2. Bertolini, L.; Elsener, B.; Pedeferri, P.; Redaelli, E.; Polder, R.B. Corrosion of Steel in Concrete-Prevention, Diagnosis, Repair Second Edition in Chinese Language; John Wiley \& Sons: Hoboken, NJ, USA, 2019.

3. Mennucci, M.; Banczek, E.; Rodrigues, P.; Costa, I. Evaluation of benzotriazole as corrosion inhibitor for carbon steel in simulated pore solution. Cem. Concr. Compos. 2009, 31, 418-424. [CrossRef]

4. Fan, L.; Bao, Y.; Meng, W.; Chen, G. In-situ monitoring of corrosion-induced expansion and mass loss of steel bar in steel fiber reinforced concrete using a distributed fiber optic sensor. Compos. Part B Eng. 2019, 165, 679-689. [CrossRef]

5. Söylev, T.A.; Richardson, M. Corrosion inhibitors for steel in concrete: State-of-the-art report. Constr. Build. Mater. 2008, 22, 609-622. [CrossRef]

6. Cabrini, M.; Fontana, F.; Lorenzi, S.; Pastore, T.; Pellegrini, S. Effect of Organic Inhibitors on Chloride Corrosion of Steel Rebars in Alkaline Pore Solution. J. Chem. 2015, 2015, 1-10. [CrossRef]

7. Diamanti, M.; Rosales, E.P.; Raffaini, G.; Ganazzoli, F.; Brenna, A.; Pedeferri, M.; Ormellese, M. Molecular modelling and electrochemical evaluation of organic inhibitors in concrete. Corros. Sci. 2015, 100, 231-241. [CrossRef]

8. Dong, Z.H.; Shi, W.; Zhang, G.A.; Guo, X.P. The role of inhibitors on the repassivation of pitting corrosion of carbon steel in synthetic carbonated concrete pore solution. Electrochimica Acta 2011, 56, 5890-5897. [CrossRef]

9. Luo, L.; De Schutter, G. Influence of corrosion inhibitors on concrete transport properties. Mater. Struct. 2008, 41, 1571-1579. [CrossRef]

10. Dong, B.; Wang, Y.; Fang, G.; Han, N.; Xing, F.; Lu, Y. Smart releasing behavior of a chemical self-healing microcapsule in the stimulated concrete pore solution. Cem. Concr. Compos. 2015, 56, 46-50. [CrossRef]

11. Wang, Y.; Fang, G.; Ding, W.; Han, N.; Xing, F.; Dong, B. Self-immunity microcapsules for corrosion protection of steel bar in reinforced concrete. Sci. Rep. 2015, 5, 18484. [CrossRef]

12. Han, N.-X.; Xing, F. A Comprehensive Review of the Study and Development of Microcapsule Based Self-Resilience Systems for Concrete Structures at Shenzhen University. Materials 2016, 10, 2. [CrossRef]

13. Xiong, W.; Tang, J.; Zhu, G.; Han, N.; Schlangen, E.; Dong, B.; Wang, X.; Xing, F. A novel capsule-based self-recovery system with a chloride ion trigger. Sci. Rep. 2015, 5, 10866. [CrossRef]

14. Wang, Y.; Ding, W.; Fang, G.; Liu, Y.; Xing, F.; Dong, B. Feasibility study on corrosion protection of steel bar in a self-immunity system based on increasing $\mathrm{OH}-$ content. Constr. Build. Mater. 2016, 125, 742-748. [CrossRef]

15. Dong, B.; Ding, W.; Qin, S.; Han, N.; Fang, G.; Liu, Y.; Xing, F.; Hong, S. Chemical self-healing system with novel microcapsules for corrosion inhibition of rebar in concrete. Cem. Concr. Compos. 2018, 85, 83-91. [CrossRef]

16. Liu, W.; Li, J.; Huang, X.; Bi, J. Corrosion Protection of Q235 Steel Using Epoxy Coatings Loaded with Calcium Carbonate Microparticles Modified by Sodium Lignosulfonate in Simulated Concrete Pore Solutions. Materials 2021, 14, 1982. [CrossRef] [PubMed]

17. Ress, J.; Martin, U.; Bosch, J.; Bastidas, D.M. pH-Triggered Release of NaNO2 Corrosion Inhibitors from Novel Colophony Microcapsules in Simulated Concrete Pore Solution. ACS Appl. Mater. Interfaces 2020, 12, 46686-46700. [CrossRef] [PubMed]

18. Liang, Z.; Wang, Q.; Dong, B.; Jiang, B.; Xing, F. Ion-triggered calcium hydroxide microcapsules for enhanced corrosion resistance of steel bars. RSC Adv. 2018, 8, 39536-39544. [CrossRef] 
19. Zhu, Y.; Ma, Y.; Yu, Q.; Wei, J.; Hu, J. Preparation of pH-sensitive core-shell organic corrosion inhibitor and its release behavior in simulated concrete pore solutions. Mater. Des. 2017, 119, 254-262. [CrossRef]

20. Zhu, Y.; Ma, Y.; Hu, J.; Zhang, Z.; Huang, J.; Wang, Y.; Wang, H.; Cai, W.; Huang, H.; Yu, Q.; et al. Adsorption of organic core-shell corrosion inhibitors on cement particles and their influence on early age properties of fresh cement paste. Cem. Concr. Res. 2020, 130, 106000. [CrossRef]

21. Bogue, R.H. Calculation of the Compounds in Portland Cement. Ind. Eng. Chem. Anal. Ed. 1929, 1, 192-197. [CrossRef]

22. Kocaba, V.; Gallucci, E.; Scrivener, K. Methods for determination of degree of reaction of slag in blended cement pastes. Cem. Concr. Res. 2012, 42, 511-525. [CrossRef]

23. Weiss, C.A.; Altaner, S.P.; Kirkpatrick, R.J. High-resolution 29Si NMR spectroscopy of 2:1 layer silicates; correlations among chemical shift, structural distortions, and chemical variations. Am. Mineral. 1987, 72, 935-942.

24. Lippmaa, E.; Maegi, M.; Samoson, A.; Engelhardt, G.; Grimmer, A.R. Structural studies of silicates by solid-state high-resolution silicon-29 NMR. J. Am. Chem. Soc. 1980, 102, 4889-4893. [CrossRef]

25. Yu, P.; Kirkpatrick, R.J.; Poe, B.; McMillan, P.F.; Cong, X. Structure of Calcium Silicate Hydrate (C-S-H): Near-, Mid-, and Far-Infrared Spectroscopy. J. Am. Ceram. Soc. 2004, 82, 742-748. [CrossRef]

26. Del Bosque, I.S.; Martinez-Ramirez, S.; Blanco-Varela, M.T. FTIR study of the effect of temperature and nanosilica on the nano structure of C-S-H gel formed by hydrating tricalcium silicate. Constr. Build. Mater. 2014, 52, 314-323. [CrossRef]

27. Puertas, F.; Palacios, M.; Manzano, H.; Dolado, J.S.; Rico, A.; Rodríguez, J. A model for the C-A-S-H gel formed in alkali-activated slag cements. J. Eur. Ceram. Soc. 2011, 31, 2043-2056. [CrossRef]

28. Sykes, D.; Kubicki, J. A model for $\mathrm{H}_{2} \mathrm{O}$ solubility mechanisms in albite melts from infrared spectroscopy and molecular orbital calculations. Geochim. Cosmochim. Acta 1993, 57, 1039-1052. [CrossRef]

29. Gutberlet, T.; Hilbig, H.; Beddoe, R. Acid attack on hydrated cement-Effect of mineral acids on the degradation process. Cem. Concr. Res. 2015, 74, 35-43. [CrossRef]

30. Bassuoni, M.; Nehdi, M. Resistance of self-consolidating concrete to sulfuric acid attack with consecutive pH reduction. Cem. Concr. Res. 2007, 37, 1070-1084. [CrossRef]

31. Andersen, M.D.; Jakobsen, H.J.; Skibsted, J. A new aluminium-hydrate species in hydrated Portland cements characterized by 27Al and 29Si MAS NMR spectroscopy. Cem. Concr. Res. 2006, 36, 3-17. [CrossRef]

32. Andersen, M.D.; Jakobsen, H.J.; Skibsted, J. Incorporation of Aluminum in the Calcium Silicate Hydrate (C-S-H) of Hydrated Portland Cements: A High-Field27Al and29Si MAS NMR Investigation. Inorg. Chem. 2003, 42, 2280-2287. [CrossRef]

33. Wang, S.-D.; Scrivener, K. 29Si and 27Al NMR study of alkali-activated slag. Cem. Concr. Res. 2003, 33, 769-774. [CrossRef]

34. Bastidas, D.; Criado, M.; Fajardo, S.; La Iglesia, A. Corrosion inhibition mechanism of phosphates for early-age reinforced mortar in the presence of chlorides. Cem. Concr. Compos. 2015, 61, 1-6. [CrossRef]

35. Tang, Y.; Zhang, F.; Hu, S.; Cao, Z.; Wu, Z.; Jing, W. Novel benzimidazole derivatives as corrosion inhibitors of mild steel in the acidic media. Part I: Gravimetric, electrochemical, SEM and XPS studies. Corros. Sci. 2013, 74, 271-282. [CrossRef]

36. $\mathrm{Hu}, \mathrm{J} . ;$ Koleva, D.; Petrov, P.; van Breugel, K. Polymeric vesicles for corrosion control in reinforced mortar: Electrochemical behavior, steel surface analysis and bulk matrix properties. Corros. Sci. 2012, 65, 414-430. [CrossRef]

37. Dubois, F.; Mendibide, C.; Pagnier, T.; Perrard, F.; Duret, C. Raman mapping of corrosion products formed onto spring steels during salt spray experiments. A correlation between the scale composition and the corrosion resistance. Corros. Sci. 2008, 50, 3401-3409. [CrossRef]

38. Koleva, D.; Hu, J.; Fraaij, A.; Stroeven, P.; Boshkov, N.; de Wit, J. Quantitative characterisation of steel/cement paste interface microstructure and corrosion phenomena in mortars suffering from chloride attack. Corros. Sci. 2006, 48, 4001-4019. [CrossRef]

39. Singh, J.; Singh, D. The nature of rusts and corrosion characteristics of low alloy and plain carbon steels in three kinds of concrete pore solution with salinity and different $\mathrm{pH}$. Corros. Sci. 2012, 56, 129-142. [CrossRef]

40. Shi, C.; Stegemann, J. Acid corrosion resistance of different cementing materials. Cem. Concr. Res. 2000, 30, 803-808. [CrossRef]

41. Möschner, G.; Lothenbach, B.; Winnefeld, F.; Ulrich, A.; Figi, R.; Kretzschmar, R. Solid solution between Al-ettringite and Fe-ettringite (Ca6[Al1-xFex(OH)6]2(SO4)3·26H2O). Cem. Concr. Res. 2009, 39, 482-489. [CrossRef] 